\title{
Interaction of Reelin with Amyloid Precursor Protein Promotes Neurite Outgrowth
}

\author{
Hyang-Sook Hoe, ${ }^{1 \star}$ Kea Joo Lee, ${ }^{2 \star}$ Rosalind S. E. Carney, ${ }^{3}$ Jiyeon Lee, ${ }^{4}$ Alexandra Markova, ${ }^{5}$ Ji-Yun Lee, ${ }^{2}$ \\ Brian W. Howell, ${ }^{6}$ Bradley T. Hyman, ${ }^{5}$ Daniel T. S. Pak, ${ }^{2}$ Guojun Bu, ${ }^{4}$ and G. William Rebeck ${ }^{1}$ \\ Departments of ${ }^{1}$ Neuroscience and ${ }^{2}$ Pharmacology, Georgetown University Medical Center, Washington, DC 20057-1464, ${ }^{3}$ Center for Neuroscience \\ Research, Children's National Medical Center, Washington, DC 20010-2970, ${ }^{4}$ Department of Pediatrics, Washington University School of Medicine, St. \\ Louis, Missouri 63110, ${ }^{5}$ Department of Neurology, Massachusetts General Hospital, MassGeneral Institute for Neurodegenerative Disorders, Charlestown, \\ Massachusetts 02129, and ${ }^{\circ}$ Neurogenetics Branch, National Institute of Neurological Disorders and Stroke Porter Neuroscience Research Center, National \\ Institutes of Health, Bethesda, Maryland 20892-3705
}

The processing of amyloid precursor protein (APP) to $A \beta$ is an important event in the pathogenesis of Alzheimer's disease, but the physiological function of APP is not well understood. Our previous work has shown that APP processing and A $\beta$ production are regulated by the extracellular matrix protein Reelin. In the present study, we examined whether Reelin interacts with APP, and the functional consequences of that interaction in vitro. Using coimmunoprecipitation, we found that Reelin interacted with APP through the central domain of Reelin (repeats 3-6) and the E1 extracellular domain of APP. Reelin increased cell surface levels of APP and decreased endocytosis of APP in hippocampal neurons in vitro. In vivo, Reelin levels were increased in brains of APP knock-out mice and decreased in APP-overexpressing mice. RNA interference knockdown of APP decreased neurite outgrowth in vitro and prevented Reelin from increasing neurite outgrowth. Knock-out of APP or Reelin decreased dendritic arborization in cortical neurons in vivo, and APP overexpression increased dendritic arborization. APP and Reelin have previously been shown to promote neurite outgrowth through interactions with integrins. We confirmed that APP interacted with $\alpha 3 \beta 1$ integrin, and $\alpha 3 \beta 1$ integrin altered APP trafficking and processing. Addition of an $\alpha 3 \beta 1$ integrin antibody prevented APP and Reelin-induced neurite outgrowth. These findings demonstrate that Reelin interacts with APP, potentially having important effects on neurite development.

\section{Introduction}

Alzheimer's disease (AD) is characterized by the presence of $\beta$-amyloid plaques, composed predominantly of the $\mathrm{A} \beta$ peptide, a 40 or 42 aa cleavage product of the amyloid precursor protein (APP). Although much is known about the processing of APP to generate or prevent generation of $\mathrm{A} \beta$ (Selkoe, 2001), relatively little is known about the physiological function of APP itself. Several lines of evidence have revealed that APP may be involved in cell adhesion, cell migration, and neurite outgrowth (Perez et al., 1997; Small et al., 1999; Siemes et al., 2006; Young-Pearse et al., 2007; Hoareau et al., 2008).

The extracellular domain of APP interacts with the extracellular matrix (ECM) protein F-spondin (Ho and Südhof, 2004; Hoe et al., 2005), and F-spondin alters the trafficking of APP and its processing to $\mathrm{A} \beta$ (Hoe et al., 2005). F-spondin also interacts

Received 0ct. 9, 2008; revised March 19, 2009; accepted April 15, 2009

This work was supported by National Institutes of Health Grants AG014473 (G.W.R.), R01 AG027924 (G.B.), R37 AG012406 (B.T.H.), and AG032330 (H.-S.H.), and the Alzheimer's Research Fund in memory of Bill and Marie Drach. We thank Drs. Andre Goffinet and Tom Curren for providing Reelin constructs and Drs. Mary Ann Stepp and Susette Mueller for integrin antibodies. We thank Drs. Sam Gandy and Paul Mathews for APP antibodies, and Drs. Yasuji Matsuoka and Baoji Xu for helpful suggestions. We also thank Ulrike Muller for the APP/APLP1 DKO tissue.

${ }^{*}$ H.-S.H. and K.J.L. contributed equally to this work.

Correspondence should be addressed to G. William Rebeck, Georgetown University, 3970 Reservoir Road Northwest, Washington, DC 20057-1464. E-mail: gwr2@georgetown.edu.

D01:10.1523/JNEUROSCI.4872-08.2009

Copyright $\odot 2009$ Society for Neuroscience $\quad$ 0270-6474/09/297459-15\$15.00/0 with members of the low-density lipoprotein (LDL) receptor family (Zisman et al., 2007) and alters axonal pathfinding (Zisman et al., 2007). Reelin is another large, multidomain, extracellular protein that interacts with members of the LDL receptor family. Reelin is expressed in Cajal-Retzius cells during embryonic neocortical development, some of which persist in the adult brain, and in a subgroup of interneurons (Miettinen et al., 2005). Reelin affects neurite outgrowth in vitro (Niu et al., 2004) and regulates neuronal migration in development via phosphorylation of the cytoplasmic adaptor protein Disabled (Dab-1). Dab-1 interacts with the cytoplasmic domains of the proteins in the LDL receptor and APP families (Gotthardt et al., 2000; Hoe et al., 2006).

Another important class of molecules involved in neurite outgrowth, cell adhesion, and cell migration is the family of integrins (DeFreitas et al., 1995; Andressen et al., 1998). Integrins are transmembrane proteins that form the link between the ECM and intracellular components (Wei et al., 2001; Demali et al., 2006). APP interacts and colocalizes with $\beta 1$ integrin (Yamazaki et al., 1997; Sabo et al., 2003), a molecule that is important for proper laminar organization and capable of enhancing neurite outgrowth (Milward et al., 1992; Qiu et al., 1995). $\beta 1$ integrin interacts with Reelin, and this interaction is important for its effects on neuronal migration (Dulabon et al., 2000). Together, these diverse findings led us to hypothesize that Reelin might be a ligand for APP and may regulate APP-mediated neurite outgrowth. 
In the present study, we examined the molecular interaction of APP with Reelin and $\alpha 3 \beta 1$ integrin, and additionally, the effect of Reelin on APP processing and $A \beta$ production. We found a novel interaction between Reelin and APP that leads to an increase in cell surface levels of APP and affects APP processing and $\mathrm{A} \beta$ production. Furthermore, we observed that interactions among Reelin, APP, and $\alpha 3 \beta 1$ integrin promote neurite outgrowth in cultured neurons and that APP and Reelin affected dendritic processes in vivo. These interactions could help explain the functions of APP in cell adhesion, neuronal migration, and neurite outgrowth.

\section{Materials and Methods}

Animal use. All animals used in the study were maintained according to protocols approved by the Animal Welfare and Use Committee at Georgetown University and adhering to all animal welfare laws. For staging of the embryos, the day of vaginal plug detection was considered as embryonic day 0 (E0), and for postnatal experiments, the day of birth was postnatal day 0 (P0). Wild-type C57BL/6J and APP knock-out mice

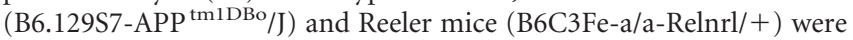
obtained from The Jackson Laboratory. APP transgenic mice (Tg2576) [129S6.Cg-Tg(APPSWE)2576Kha N20] and wild-type C57/BL/B6SJLF1 were obtained from Taconic Farms.

Vector construction. We produced several deletion constructs of human APP770. Each APP construct was generated with a signal peptide and a C-terminal myc tag in the pSecTag2/HygroB expression vector. We also generated a secreted APP-Fc fusion construct. Additionally, we generated constructs of mouse $\alpha 3$ and $\beta 1$ integrins with a signal peptide and an N-terminal hemagglutinin (HA) tag. The recombinant DNA was confirmed by sequencing, and expression of correctly sized proteins was confirmed by Western blotting. Reelin and several deletion constructs of Reelin with C-terminal myc tags were kind gifts from Dr. Andre Goffinet (University of Louvain, School of Medicine, Brussels, Belgium).

Antibodies. The following antibodies were used: anti-HA (Abcam), anti-c-myc (Abcam), anti- $\alpha \mathrm{M}$ (R\&D Systems), anti- $\alpha 3 \beta 1$ (Millipore Bioscience Research Reagents), and anti- $\alpha 5 \beta 1$ (Millipore Bioscience Research Reagents). For analysis of APP, APP antibodies recognizing the extracellular domain of APP (Sigma-Aldrich) (22C11, Millipore Bioscience Research Reagents) and a 6E10 antibody identifying secreted $\operatorname{APP} \alpha(\operatorname{sAPP} \alpha)$ and $\beta$-C-terminal fragment $(\beta$-CTF) (Signet) were used. Dr. Paul Mathews (Nathan S. Kline Institute, Orangeburg, NY) provided antibody c1/6.1, and Dr. Sam Gandy (Thomas Jefferson University, Philadelphia, PA) provided antibody 369 , both of which recognize the $\mathrm{C}$ terminus of APP. Reelin was recognized using the monoclonal antibody G10 (Calbiochem).

Primary and secondary cell lines and culture conditions. COS7 and Neuro2a cells were maintained in Opti-MEM (Invitrogen) with 10\% FBS. Reelin and control conditioned media were prepared as described previously (Chen et al., 2004). Briefly, COS7 cells were transfected with Reelin plasmids or with an empty pSecTag2/HygroB vector. After $24 \mathrm{~h}$, cells were incubated in Opti-MEM serum-free medium, and conditioned medium was collected at $48 \mathrm{~h}$ after transfection. Conditioned medium was concentrated 50-fold using a Centricon centrifugal filter with a 10,000 molecular-weight cutoff (Millipore), aliquoted and stored at $-80^{\circ} \mathrm{C}$.

Primary mouse embryonic cortical neuron cultures were prepared from E16 Swiss-Webster mice as previously described (Qiu et al., 2002). Brain cortices were chopped and trypsinized for $10 \mathrm{~min}$ at $37^{\circ} \mathrm{C}$. After trypsinization, $0.4 \mu \mathrm{g} / \mathrm{ml}$ trypsin inhibitor, $0.025 \% \mathrm{DNase}$, and $12 \mathrm{~mm}$ $\mathrm{MgSO}_{4}$ were added and mixed until tissue was thoroughly homogenized. Cells were then transferred to Neurobasal medium containing B27 serum supplement, $1 \mathrm{~mm}$ glutamine, gentamycin, and Ara-C (Sigma-Aldrich). Neurons were seeded on $50 \mu \mathrm{g} / \mathrm{ml}$ poly-D-lysine-coated 12 well tissue culture plates at a density of $2 \times 10^{6}$ cells per well.

Primary hippocampal neurons from E18-E19 Sprague Dawley rats were cultured at 150 cells $/ \mathrm{mm}^{2}$ as described previously (Pak et al., 2001). Neurons were transfected at 10 or $12 \mathrm{~d}$ in vitro (DIV) by calcium phosphate precipitation ( $4-5 \mu \mathrm{g}$ of DNA per well). Six or $8 \mathrm{~d}$ after transfec- tion, we analyzed cell surface expression levels of APP and endocytosis of APP in vitro (DIV 16-18) (see below).

Purification of the APP-Fc fusion protein. Soluble ectodomains of APP fused to human Fc were expressed in COS7 cells. Two days later, the medium was collected and centrifuged at $15,000 \mathrm{rpm}$, at $4^{\circ} \mathrm{C}$ for $15 \mathrm{~min}$ using a Sorvall SS34 centrifuge. A Pro-G-Sepharose column was equilibrated using binding buffer ( $50 \mathrm{~mm}$ Na phosphate, $\mathrm{pH}$ 6; $500 \mathrm{~mm} \mathrm{NaCl}$ ), before applying the centrifuged medium to the washed column, which was followed by two more washes with $100 \mathrm{ml}$ of binding buffer. We then eluted the protein with elution buffer ( 0.1 M glycine, $\mathrm{pH} 2.7)$, collecting 3 $\mathrm{ml}$ of elute per tube, and the first tube was discarded. After nine fractions, we added more binding buffer to ensure optimal recovery of the protein. To each of the fractions, we immediately added $150 \mu \mathrm{l}$ of K-phosphate to neutralize the $\mathrm{pH}$. The fractions were centrifuged with a YM-100 filter to eliminate any calf serum Ig and then with a YM-10 filter to concentrate the fusion protein (Millipore).

Coimmunoprecipitations. Transfected COS7 cells were washed with PBS and lysed in buffer containing $50 \mathrm{~mm}$ Tris- $\mathrm{HCl}, \mathrm{pH}$ 8.0, $0.15 \mathrm{M} \mathrm{NaCl}$, $1 \%$ Nonidet P-40, phosphatase inhibitors (Sigma-Aldrich), and protease inhibitors (Roche). For immunoprecipitation, the lysates were incubated for $2 \mathrm{~h}$ at $4^{\circ} \mathrm{C}$ with the anti-myc antibody or an anti-C1/6.1 antibody bound to protein G-Sepharose beads (GE Healthcare). The precipitates were then washed three times with lysis buffer and resuspended in SDS sample buffer. For APP pull-down assays, we incubated protein G-Sepharose beads with the ectodomain of APP protein and control or Reelin conditioned medium for $24 \mathrm{~h}$ at $4^{\circ} \mathrm{C}$ with the anti-Reelin antibody. Protein A/G-Sepharose beads were washed five times with lysis buffer and resuspended in SDS sample buffer. The samples were separated by SDS-PAGE on $4-15 \%$ polyacrylamide gels, transferred onto a polyvinylidene difluoride (PVDF) membrane, and blocked with 5\% nonfat dry milk. The blots were incubated with antibodies at room temperature for $1 \mathrm{~h}$. Horseradish peroxidase-conjugated secondary antibodies were visualized using an enhanced chemiluminescence detection system and exposed to film.

Measurement of APP proteolytic fragments by Western blot and ELISA. COS7 cells were transiently transfected with APP using Fugene 6 (Roche) according to the manufacturer's protocol and cultured in DMEM containing 10\% FBS for $24 \mathrm{~h}$. Cells were maintained for another $24 \mathrm{~h}$ in serum-free media with or without Reelin conditioned medium. Proteins from cell extracts or conditioned media were separated using Trisglycine PAGE. Proteins were transferred onto a PVDF membrane and probed with relevant primary antibodies for $1 \mathrm{~h}$ at room temperature. Horseradish peroxidase-conjugated secondary antibody was visualized by ECL detection system (Pierce) and exposed to film. Secreted fragments were determined from the media ( $\mathrm{sAPP} \alpha ; 6 \mathrm{E} 10$ antibody). CTFs were measured by Western blot from cell lysates (APP CTF; C1/6.1). $\mathrm{A} \beta 40$ and $\mathrm{A} \beta 42$ levels in the conditioned media were determined by ELISA, using $1 \mathrm{~A} 10$ (anti-A $\beta 40$ ) or $1 \mathrm{C} 3$ (anti-A $\beta 42$ ) as capture antibodies and 12B2, which recognizes both mouse and human $\mathrm{A} \beta$, as a detection antibody (Immunobiological Laboratories) (Horikoshi et al., 2004).

Biotin-labeled cell surface proteins. COS7 cells were transiently transfected with APP and cultured for $24 \mathrm{~h}$ in DMEM containing 10\% FBS. After $24 \mathrm{~h}$, serum-free medium was added with or without Reelin conditioned medium. After $24 \mathrm{~h}$, cells were washed and surface proteins were labeled with Sulfo-NHS-SS-Biotin at $500 \mu \mathrm{g} / \mathrm{ml}$ PBS (Pierce) under gentle shaking at $4^{\circ} \mathrm{C}$ for $30 \mathrm{~min}$. After quenching, cells were lysed, disrupted by sonication, and clarified by centrifugation $(10,000 \times g ; 2 \mathrm{~min})$. To isolate biotin-labeled proteins, lysate was added to immobilized NeutrAvidin TM Gel and incubated for $1 \mathrm{~h}$ at room temperature. Gels were washed and incubated with SDS-PAGE sample buffer including $50 \mathrm{~mm}$ DTT. Eluants were analyzed for APP by immunoblotting.

Live cell surface staining. Surface immunostaining in hippocampal neurons was performed as described previously (Hoe et al., 2007). Briefly, neurons were transfected with APP fused at its $\mathrm{N}$ terminus to the green fluorescent protein (GFP-APP) at 10 or 12 DIV by calcium phosphate precipitation. Live cultures were incubated with $6 \mathrm{E} 10$ or APP $\mathrm{N}$-terminal antibody ( $10 \mu \mathrm{g} / \mathrm{ml}$ in conditioned medium) for $10 \mathrm{~min}$ to specifically label surface APP, then lightly fixed for $5 \mathrm{~min}$ in $4 \%$ paraformaldehyde (4\% PFA) (nonpermeabilizing conditions). After fixation, 
antibody-labeled APP (surface APP) was detected with Alexa Fluor 555linked anti-mouse or anti-rabbit secondary antibodies for $1 \mathrm{~h}$. The cells were then washed in PBS and permeabilized by incubating the coverslips in cold $\left(-20^{\circ} \mathrm{C}\right)$ methanol for $90 \mathrm{~s}$. Total levels of APP were measured by GFP immunostaining, using Alexa Fluor 488-linked secondary antibodies.

Internalization assay. The surface APP internalization assay was performed as described previously (Hoogenraad et al., 2005). Cultured hippocampal neurons transfected with GFP-APP constructs were treated with or without Reelin for $24 \mathrm{~h}$. Cells were incubated live with $6 \mathrm{E} 10$ or APP N-terminal antibodies $(10 \mu \mathrm{g} / \mathrm{ml}$ in conditioned medium) for 10 min without cell permeabilization to label surface APP. After a brief wash with prewarmed DMEM, cells were placed in conditioned medium with or without Reelin, and incubated at $37^{\circ} \mathrm{C}$ for $30 \mathrm{~min}$ to allow for internalization of labeled APP. After fixation in 4\% PFA for $5 \mathrm{~min}$, the surfaceremaining antibody-labeled APP was saturated with Alexa 647-linked anti-rabbit secondary antibody for $2 \mathrm{~h}$. The internalized cell surface APP was subsequently labeled with Alexa 555-conjugated anti-mouse or antirabbit secondary antibodies for $1 \mathrm{~h}$ after cell permeabilization in $-20^{\circ} \mathrm{C}$ methanol.

Quantitation and image analysis. Images were collected using a Zeiss LSM510 confocal microscope (Carl Zeiss). Confocal $z$-series image stacks encompassing entire neurons were analyzed using MetaMorph software (Molecular Devices). For measures of surface or internalized APP, dendrites from hippocampal neurons were carefully traced and surface fluorescence intensities were determined for the traced region.

Golgi staining and analysis of dendrite morphology in vivo. Golgi staining was performed on APP Tg2576 (4 weeks of age; $n=4$ ), APP knockout mice ( 4 weeks of age; $n=4$ ), Reeler mice ( 3 weeks of age; $n=4$ ), and wild-type littermates ( 3 weeks of age; $n=4$ for each group). For these experiments, we used FD Rapid GolgiStain kit (FD NeuroTechnologies). The dissected brains were immersed in solution A and B for 2 weeks at room temperature and transferred into solution $\mathrm{C}$ for $24 \mathrm{~h}$ at $4^{\circ} \mathrm{C}$. The brains were sliced using a Vibratome (VT1000S; Leica) at a thickness of $150 \mu \mathrm{m}$. Bright-field microscopy (Axioplan 2; Zeiss) images (at 63× magnification) were taken of pyramidal neurons in cortical layers II/III in APP Tg2576 and APP knock-out mice brains and compared with their wild-type equivalents. In Reeler mice, cortical layer formation was severely disrupted, which caused difficulties identifying pyramidal neurons in specific layers. However, we observed some pyramidal neurons that exhibited preserved orientation of apical and basal dendrites. For image analysis, primary length was measured from the cell body to a branching point from which secondary dendrites bifurcate. Secondary dendritic length was measured to a branching point from which trimeric dendrites bifurcate. The numbers of primary and secondary dendrites per neuron were counted. Neurolucida software (MicroBrightField) was used to trace dendrites.

Sholl analysis. Using the center of the soma as a focal point, we generated concentric circles around the center. The initial circle was of $10 \mu \mathrm{m}$ radius and each circle increased the radius by $10 \mu \mathrm{m}$ increments. We counted the number of intersections on the perimeter of each circle per neuron. A total of 100 neurons was used in this analysis.

Lentiviral constructs and short hairpin RNA production. APP constructs were introduced into plasmid FSW lentiviral vectors under the synapsin promoter. To generate the APP short hairpin RNA (shRNA), target sequences were designed against rat APP and used to synthesize oligonucleotides comprising a forward and reverse sequence separated by a linker sequence (CGAA). Lentiviral vectors expressing shRNA were then constructed using the BLOCK-iT system according to manufacturers' instructions (Invitrogen). Briefly, oligonucleotides were ligated into the pLL 3.7 vector. Two target sequences (APP-7, GGTGCCTAGTTGGTGAGTT; APP-14, GCACTAACTTGCACGACTA) proved competent for reduction of APP expression. To produce the lentivirus, 293FT cells were transiently transfected with constructs: $5 \mu \mathrm{g}$ of VSVg, $15 \mu \mathrm{g}$ of $\delta-8.9$, and $20 \mu \mathrm{g}$ of promoter-reporter plasmid. Approximately $4 \mathrm{~h}$ after transfection, the medium was changed and incubated for an additional $48-60 \mathrm{~h}$. The virus was concentrated and stored at $-80^{\circ} \mathrm{C}$. Primary neurons were infected with FSW vector, APP, or APP shRNA for $3 \mathrm{~d}$.

Statistical analyses. All data were analyzed with GraphPad Prism 4 software using either Student's $t$ test or one-way ANOVA followed by a Newman-Keuls post hoc test. Descriptive statistics were displayed as an expressed mean \pm SEM. Differences were deemed significant when $p<0.05$.

\section{Results \\ Reelin interacts with APP in primary hippocampal neurons and brain lysates}

To examine whether APP and Reelin physically interacted in mouse brain lysates, we immunoprecipitated APP and probed the precipitates for Reelin. Immunoprecipitation of APP resulted in coprecipitation of the $300 \mathrm{kDa}$ form of Reelin (Fig. 1A). Reelin was not detected in control experiments performed with a control antibody [ $\alpha$-phospho-c-Jun N-terminal kinase ( $\alpha$-P-JNK)] (Fig. $1 A$ ). We also immunoprecipitated Reelin from brain lysates and probed the precipitates with APP. In confirmation of the previous result, APP coprecipitated with Reelin (Fig. $1 B$ ). As another control for these experiments, we examined brains from APP/APLP1 double knock-out (APP/APLP1 DKO) mice. The APP immunoprecipitation resulted in Reelin precipitation from wild-type, but not from APP/APLP1 DKO mouse brains (Fig. $1 C)$. Immunoprecipitation of APP from primary cortical neurons resulted in coprecipitation of Reelin (Fig. 1D). We also identified a similar coprecipitation of APP with Reelin in COS7 cells transfected with APP and Reelin cDNAs (supplemental Fig. $1 A, B$, available at www.jneurosci.org as supplemental material). To further confirm the interactions with APP and Reelin, we generated a purified secreted APP-Fc fusion protein. We precipitated anti-Fc with protein $\mathrm{G}$ and ran a Western blot for Reelin (supplemental Fig. 1C, top panel, available at www.jneurosci.org as supplemental material). We also did the reverse experiment, immunoprecipitating with anti-Reelin and probing with anti-Fc (supplemental Fig. $1 C$, middle panel, available at www.jneurosci.org as supplemental material). We found that Reelin coprecipitated with APP. Additionally, we also conducted a control experiment to ensure that Reelin was not interacting with the Fc control vector (supplemental Fig. $1 D$, available at www.jneurosci.org as supplemental material). For this experiment, we used purifed Fc control vector or APP-Fc protein. We immunoprecipitated with anti-Reelin in both conditions and ran a Western blot with anti-Fc. We found that Reelin interacted with APP but not with the control Fc vector (supplemental Fig. $1 D$, available at www.jneurosci.org as supplemental material).

To test whether Reelin and APP colocalize in primary hippocampal neurons, we immunostained primary neurons at DIV 14 with antibodies against Reelin and APP. Reelin showed strong expression in the cell body and punctate patterns along the dendrites in $\sim 25 \%$ of the hippocampal neurons. APP showed strong expression in the cell body and punctate patterns along the dendrites in all of the hippocampal neurons. Colocalization of APP with Reelin was observed throughout dendritic regions of hippocampal neurons (Fig. $1 E$ ).

In the controls to the above experiments, we were interested to observe increased levels of Reelin in APP/APLP1 DKO mouse brains compared with brains of control mice (Fig. 1C, bottom panels, both the $300 \mathrm{kDa}$ and $180 \mathrm{kDa}$ forms of Reelin). To test whether the Reelin levels were altered by APP in vivo, we performed Western blot analysis of Reelin in brain lysates from APP single knock-out mice and APP-overexpressing mice (Tg2576). The pattern of Reelin immunoreactivity was strikingly different in the APP knock-out brains (Fig. 1F). The levels of the 300 and $180 \mathrm{kDa}$ forms of Reelin were consistently increased in 1-year-old APP knock-out mice compared with control C57/BL/6J mice 
A

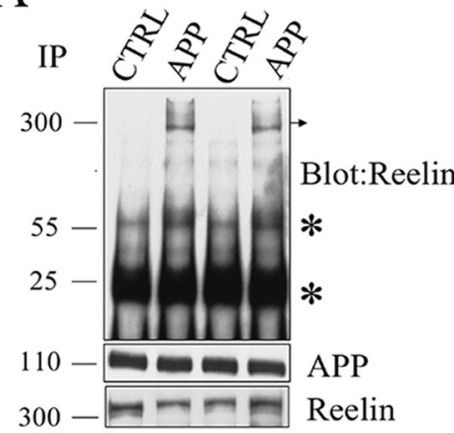

C

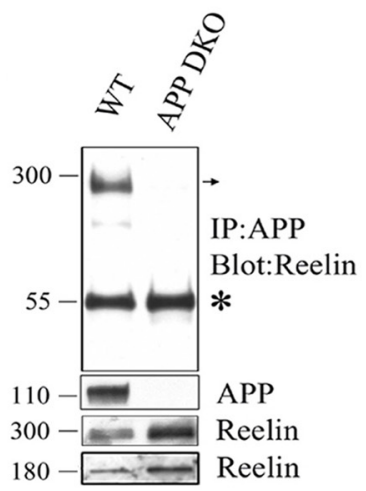

B

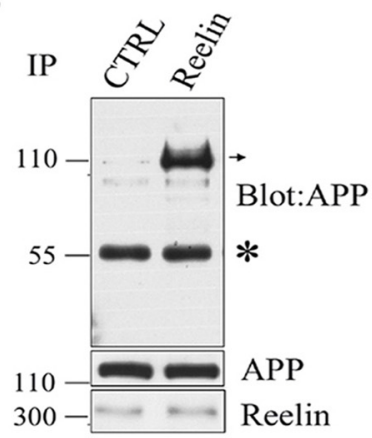

D

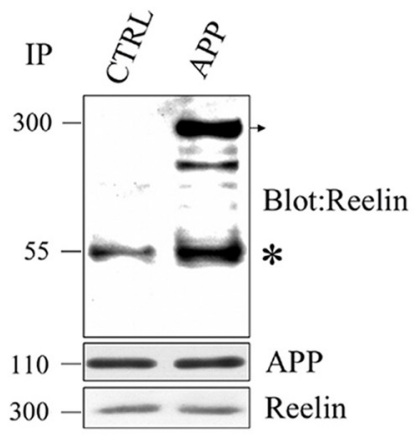

F

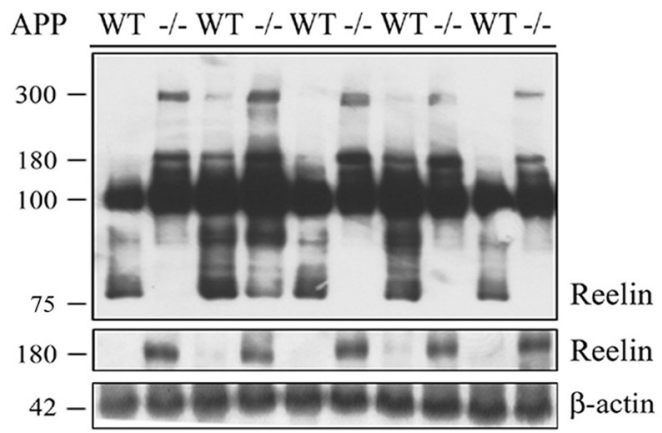

G

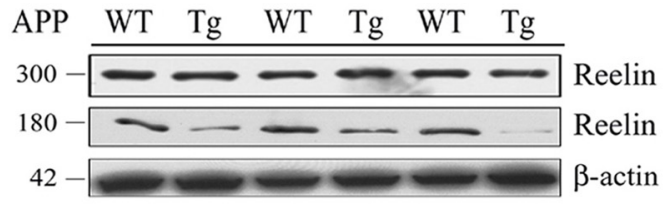

$\mathrm{H}$

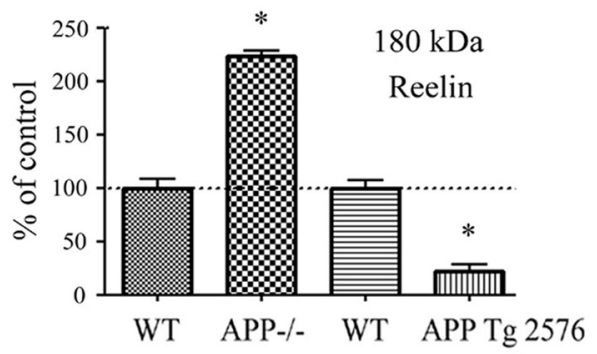

E13 E17 P1 P6 P10 P36

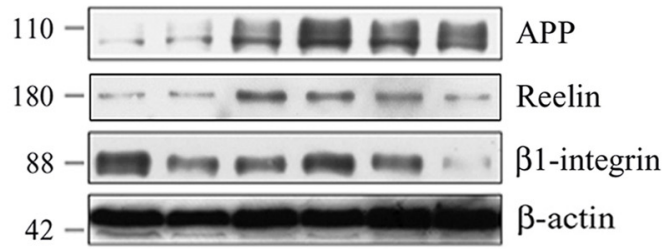

Figure 1. Reelin interacts with APP in primary cortical neurons and mouse brain. $A$, Mouse brain lysates $(200 \mu \mathrm{g})$ were immunoprecipitated with $22 C 11$ antibody against APP and probed with an anti-Reelin antibody (lanes 2 and 4). As a negative control, an irrelevant antibody ( $\alpha$-P-JNK) was included in the experiment (lanes 1 and 3 ). The asterisks denote antibody heavy and light chains. The bottom panels demonstrate total levels of APP and $300 \mathrm{kDa}$ Reelin in the different cell lysates. B, Mouse brain lysates $(200 \mu \mathrm{g})$ were immunoprecipitated with anti-Reelin antibody and probed with 22C11 antibody against APP (lane 2). C, Mouse brain lysates from wild-type and APP/APLP1 DKO were immunoprecipitated with anti-APP antibody and probed with anti-Reelin antibody. Interaction of APP with Reelin was detected in brain lysates from wild-type mice, but not from APP/APLP1 DK0 mice. D, Primary cortical neuronal lysates were immunoprecipitated with anti-APP antibody and probed with the antibody against Reelin. Levels of APP or Reelin were measured in lysates from A-D.E, Cultured hippocampal neurons were fixed and immunostained at DIV 14 for APP and Reelin. Primary antibodies were detected with Alexa Flour 488 anti-rabbit antibody (in green; left panel) and Alexa Fluor 555 anti-mouse antibody (in red; middle panel). Immunolabeled neurons were imaged by confocal microscopy $(63 \times)$. Colocalization of APP and Reelin appears as yellow in the right panel. $\boldsymbol{F}$, Levels of both the 300 and $180 \mathrm{kDa}$ forms of Reelin were detected using Western blot analyses with G10 antibody and compared between APP-deficient mice $(n=5)$ and wild-type mice $(n=5)$. Increased levels of the 300 and $180 \mathrm{kDa}$ (top panel) were observed in the brain lysates from APP knock-out mice in comparison with wild-type mice for APP ${ }^{-1-}$. Additional Western blot analysis confirmed these observations for the $180 \mathrm{kDa}$ (middle panel) and $300 \mathrm{kDa}$ (data not shown). G, Levels of 300 and $180 \mathrm{kDa}$ forms of Reelin were compared between APP Tg2576 mice $(n=3)$ and wild-type controls for APP Tg2576 mice $(n=3)$. $\boldsymbol{H}$, Quantification of the levels of the Reelin $180 \mathrm{kDa}$ band in four different Western blots ( 2 of which are shown in $\boldsymbol{F}$ and $\boldsymbol{G}$ ) show that Reelin was increased in APP knock-out mice $\left(n=5 ;\right.$ by $133 \%$; $\left.{ }^{*} p<0.01\right)$ and decreased in $\operatorname{APP} \operatorname{Tg} 2576$ mice $\left(n=3\right.$; by $87 \%$; $\left.{ }^{*} p<0.01\right)$. Error bars indicate SEM. I, Levels of APP, Reelin, and $\beta 1$-integrin in mouse brain were examined by Western blots at various developmental stages ( $n=3$ at each age). APP was increased between P1 and P36, a critical period for development of neuronal processes and synaptogenesis. Levels of Reelin were also highest between P1 and P10.

(Fig. $1 F$, first and second panels). In 1 -year-old Tg2576 mice, the larger $300 \mathrm{kDa}$ form of Reelin was not altered compared with controls C57/BL/B6SJLF1, whereas the level of the $180 \mathrm{kDa}$ form of Reelin was decreased (Fig. 1G). Quantification of the $180 \mathrm{kDa}$ band for Reelin using four different Western blots demonstrated that Reelin was significantly $(133 \%)$ increased in $\mathrm{APP}^{-1-}$ mice compared with wild-type controls for APP $(p<0.01, n=5)$ (Fig. $1 H$ ), and significantly (87\%) decreased in APP Tg2675 mice compared with wild-type controls for APP Tg2576 $(p<0.01)$ (Fig. $1 H$ ). These findings suggest an interaction between APP and Reelin that is important for maintaining normal Reelin levels in the brain. 
We next tested whether APP and Reelin colocalized in the embryonic and postnatal brain. APP and Reelin levels are highest between $\mathrm{P} 1$ and $\mathrm{P} 10$, an important period for synaptogenesis (Fig. 1I). We also tested for levels of $\beta 1$ integrin, since it has been found to interact with both APP and Reelin. $\beta 1$ integrin levels were more variable from E13 to P10 and sharply lower at P36 (Fig. 1I). Thus, the timing of expression is consistent with the idea that all three proteins play a role in neuronal development and circuitry formation.

\section{Reelin domain 3-6 interacts with APP domain E1}

To determine which domain of Reelin interacts with APP, we cotransfected COS7 cells with full-length APP and various Reelin constructs containing C-terminal myc tags (Fig. $2 \mathrm{~A}$, constructs R1-R6). Reelin consists primarily of eight structural repeats, and we analyzed constructs with various repeats deleted. Proteins of variable sizes were measured with conditioned medium expressed from Reelin constructs R1-R5, as determined by Western blotting with a myc antibody (Fig. $2 \mathrm{~B}$, left panel) (Jossin et al., 2003). For Reelin construct R6, we observed $\sim 300$ and $180 \mathrm{kDa}$ fragments, supportive of the extracellular cleavages of Reelin reported in previous studies (Fig. $2 \mathrm{~B}$, right panel) (Jossin et al., 2003). Using cell lysates containing the various Reelin constructs, we immunoprecipitated APP, and probed for Reelin with an antic-myc antibody. APP precipitated each of the first four Reelin constructs containing the repeats from 3 to 6 (Fig. 2C). However, the Reelin construct containing repeats $7-8$ did not coprecipitate with APP.

We examined which domain of APP mediates the interaction with Reelin. COS7 cells were transfected with an N-terminal construct of Reelin (Fig. 2A, construct R6) and APP deletion constructs containing myc tags (Fig. 2D). Proteins of expected sizes were expressed from each APP construct, as determined by Western blotting (Fig. 2E). We immunoprecipitated Reelin and probed for APP (anti-myc). APP constructs containing all or most of its extracellular domain (constructs A1 and A4) immunoprecipitated with Reelin (Fig. $2 F$ ), but the construct containing only amino acids 430-770 (construct A2) did not. Conversely, we immunoprecipitated with anti-myc (for APP) and probed for Reelin. We found that Reelin coprecipitated with APP constructs A1 and A4, but not with the APP intracellular domain (construct A3) (Fig. 2G). To further define the extracellular domain of APP that binds Reelin, we transfected COS7 cells with the $\mathrm{N}$-terminal construct of Reelin (R6) and APP deletion constructs containing only the E1 or the E2 extracellular domains (Fig. $2 \mathrm{H}$, constructs A5 and A6). We found that the E1 domain of APP immunoprecipitated with Reelin, but the E2 domain did not (Fig. $2 I$ ). For these experiments to determine interacting domains of APP and Reelin, we used coexpression systems, so we did not determine whether the APP-Reelin interactions occurred intracellularly or extracellularly. In subsequent experiments, we treated cells with Reelin extracellularly, to specifically examine the biological effects of Reelin.

\section{Reelin increases cell surface APP and its processing}

To examine whether extracellular Reelin altered the cellular trafficking of APP, we transfected COS7 cells with APP and then treated them with Reelin-containing medium in a timedependent manner. Cell surface proteins were biotinylated, isolated with avidin beads, and immunoblotted for APP. Reelin treatment increased cell surface APP at 6, 12, and $24 \mathrm{~h}$. However, after $48 \mathrm{~h}$ of Reelin treatment, cell surface levels of APP were decreased compared with the earlier time points (Fig. 3A). Quan- tification demonstrated that Reelin significantly increased cell surface levels of APP at 6, 12, and 24 h (Fig. $3 B)(n=3$; by 39, 77, and $69 \%$, respectively; ${ }^{\star} p<0.05$ ). To test whether there were changes in cell surface expression of APP in the absence of Reelin, we transfected COS7 cells with APP and then treated them with control conditioned medium using the same method described above. Control treatment increased cell surface APP by $36 \%$ at $6 \mathrm{~h}$. However, after $12 \mathrm{~h}$ of control treatment, cell surfaces levels of APP were similar to untreated cells (Fig. $3 C, D$ ). Thus, we conclude that Reelin caused long-lived effects on cell surface APP trafficking.

We also examined surface APP levels in cultured cortical neurons and found similarly increased surface levels of endogenous APP after 24 h of Reelin treatment (Fig. 3E) (53\% increase compared with control cells; $p<0.05 ; n=3$ ). As an independent assay to measure the cell surface levels of APP, we performed a FACSCalibur in Neuro2A cells. Neuro2A cells stably expressing APP were treated with control or Reelin for $30 \mathrm{~min}$. Cells were then incubated with anti-APP antibody on ice to label the cell surface APP and analyzed by flow cytometry. Consistent with the previous assay, Reelin treatment increased cell surface levels of APP in Neuro2A cells (data not shown).

We also tested whether Reelin altered surface APP levels using live-cell immunostaining. We transfected hippocampal neurons with plasmid expressing a GFP-APP fusion protein (to increase the assay signal) and treated them with Reelin for $24 \mathrm{~h}$. To specifically label surface APP, we incubated live neurons with APP $\mathrm{N}$-terminal antibody for $10 \mathrm{~min}$ without permeabilization. After a brief wash and light fixation in 4\% PFA, the surface-remaining antibody-labeled APP was labeled with anti-mouse or anti-rabbit secondary antibodies conjugated to Alexa Fluor 555 for $1 \mathrm{~h}$. Total levels of APP were measured by GFP immunostaining after permeabilization. Fluorescent intensity of cell surface APP immunostaining was increased in the presence of Reelin in neurons (Fig. $3 F)$. Quantitative analysis revealed a 36\% increase in levels of cell surface of APP by Reelin $(p<0.01 ; n=10)$. Thus, three independent assays demonstrated increased surface APP levels induced by Reelin.

We reasoned that the interaction between Reelin and surface APP might reduce internalization of APP, resulting in the increased surface levels of APP. To test this hypothesis, we conducted an internalization assay of APP (Fig. 3G). Hippocampal neurons transfected with GFP-APP constructs were treated with or without Reelin for $24 \mathrm{~h}$. After having surface APP labeled with APP N-terminal antibodies, cells were returned to the conditioned medium and incubated for $30 \mathrm{~min}$ to allow for internalization of labeled APP. We then stained the surface-remaining APP N-terminal antibody-labeled APP with Alexa 647-linked anti-rabbit IgG antibody. The internalized cell surface APP was subsequently labeled with Alexa 555-conjugated anti-mouse IgG antibodies after cell permeabilization. Quantification of both total APP (GFP signal) and internalized APP revealed that Reelin significantly decreased internalization of APP by $41 \%(p<0.05$; $n=10)$.

These changes to APP trafficking by Reelin suggested that Reelin may also alter APP processing. Thus, we transfected COS7 cells with APP and treated cells with control or Reelin-containing medium for $24 \mathrm{~h}$. Secreted APP measured in conditioned medium, and full-length APP and APP CTF were assayed in cell lysates. Reelin treatment increased secreted APP $\alpha$ in conditioned media and total APP CTF in cell lysates (Fig. $3 H$ ), both consistent with increased $\alpha$-cleavage of APP. Reelin treatment significantly decreased levels of secreted $A \beta 40$ and $A \beta 42$ as determined by 


\section{A. Structure of Reelin}

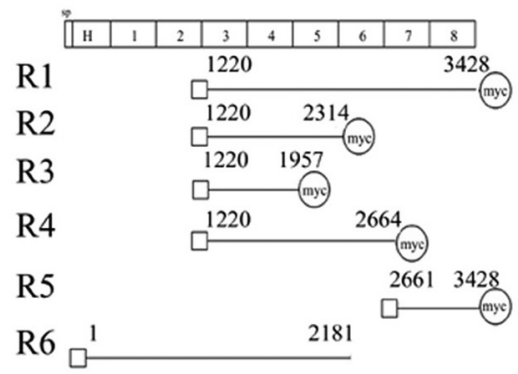

B

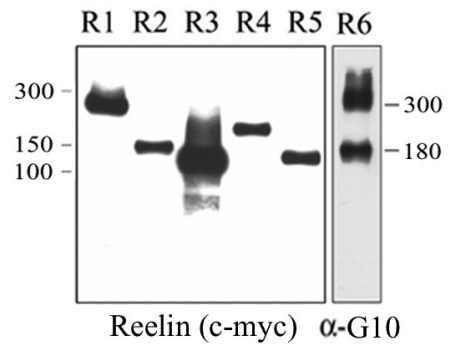

$\mathrm{C}$

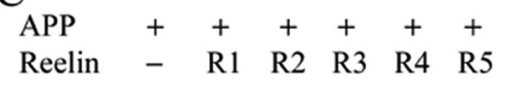

Reelin - R1 R2 R3 R4 R5

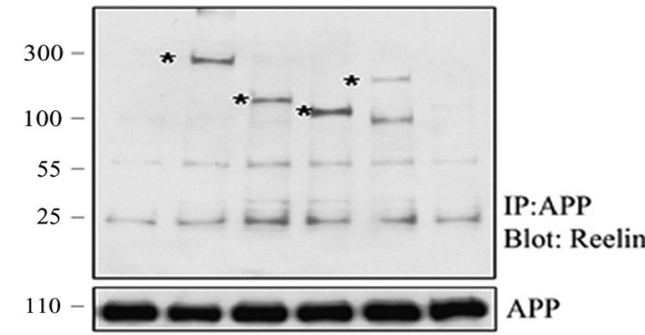

$\mathrm{F}$

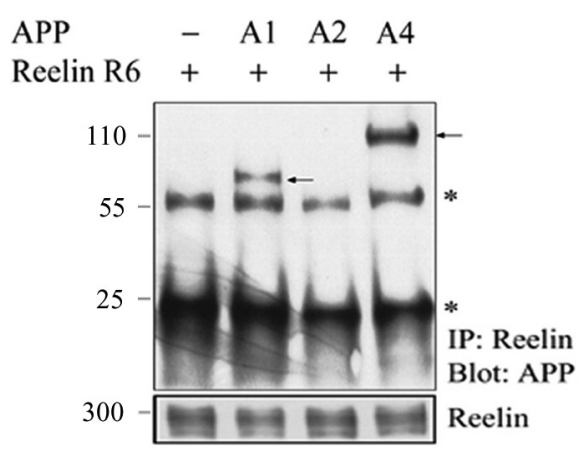

G

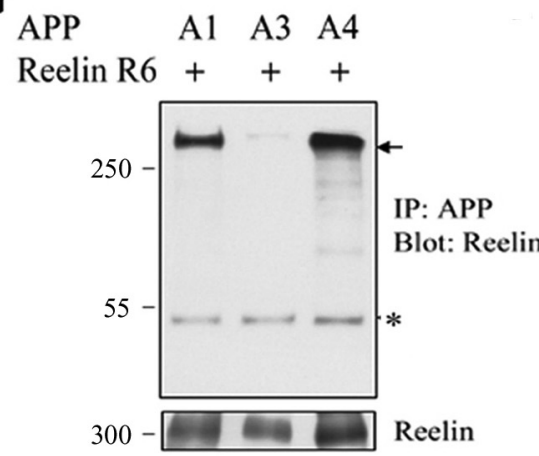

$\mathrm{E}$

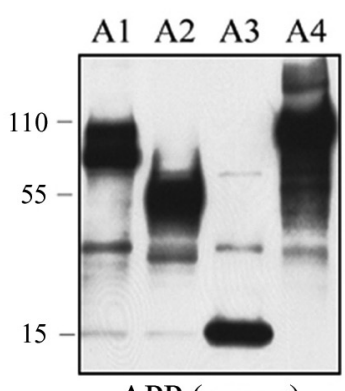

$\mathrm{H}$

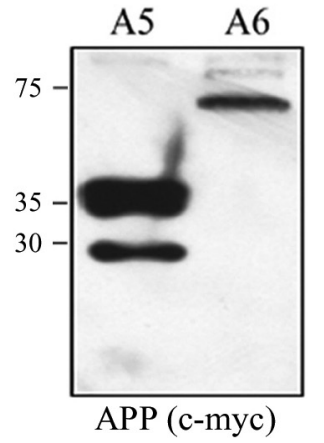

I

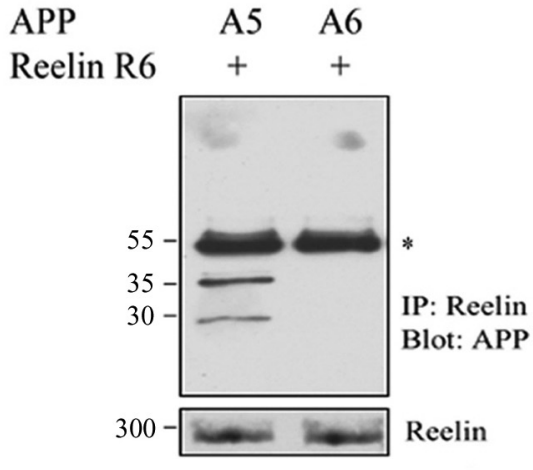

Figure 2. The Reelin 3-6 domain interacts with the APP E1 domain. $\boldsymbol{A}$, Schematic diagrams of Reelin constructs, with rectangles indicating signal peptides and circles indicating myc tags. $\boldsymbol{B}$, Western blot analysis showing comparable expression levels of different Reelin constructs. C, COS7 cells were transfected with plasmids expressing different Reelin C-terminal constructs (indicated along the top of the panel) and APP. Cell lysates $(200 \mu \mathrm{g})$ were immunoprecipitated with an anti-6E10 antibody and probed with an anti-myc antibody. Reelin constructs containing $3-6$ domains coimmunoprecipitated with APP (constructs R1-R4), whereas the Reelin construct containing the 7-8 domains (construct R5) did not. The APP immunoblotting (bottom panel) showed similar expression levels of APP in all transfected cells. $\boldsymbol{D}$, Schematic diagram of APP constructs. $\boldsymbol{E}$, Western blot analysis with an anti-myc antibody exhibiting expression levels of individual APP constructs. $\boldsymbol{F}$, COS7 cells were transfected with different APP constructs (indicated along the top of the film) and an N-terminal construct of Reelin (construct R6). Cell lysates (200 $\mu$ g) were immunoprecipitated with anti-G10 and probed with anti-myc antibody. Reelin was immunoprecipitated with APP constructs containing the extracellular domain (constructs A1 and A4), but not with APP construct containing 430-770 aa (construct A2). G, COS7 cells were transfected with different APP constructs (indicated along the top of the film) and an N-terminal construct of Reelin (construct R6). Cell lysates $(200 \mu \mathrm{g})$ were immunoprecipitated with anti-myc and probed with $\mathrm{G} 10$ antibody. Reelin was immunoprecipitated with full-length APP and the construct containing the extracellular domain of APP (constructs A1 and A4), but not with the construct containing intracellular domain of APP (construct A3). The Reelin immunoblot (bottom panel) showed comparable expression levels of Reelin in all transfected cells. $\boldsymbol{H}$, Western blot with anti-myc antibody demonstrating expression levels of APP E1 and APP E2 domain. I, COS7 cells were cotransfected with N-terminal construct of Reelin (construct R6) and either APP E1 domain or APP E2 domain. Cell lysates (200 $\mu \mathrm{g}$ ) were immunoprecipitated with G10 and probed with anti-myc antibody. Coimmunoprecipitation of Reelin was only detected when transfected with the construct containing the APP E1 domain (construct A5), but not with APP E2 domain (construct A6). The Reelin immunoblot (bottom panel) showed similar expression levels of Reelin in all transfection conditions. The asterisks shown in $\boldsymbol{F}, \boldsymbol{G}$, and $\boldsymbol{I}$ indicate $\lg \mathbf{G}$ heavy and light chains.

ELISA ( $n=6$; by 75 and $54 \%$, respectively; $\left.{ }^{\star} p<0.01\right)$. These data suggest that Reelin increased $\alpha$-cleavage of APP and decreased its $\beta$-cleavage. These findings are consistent with our previous data showing Reelin decreased $\mathrm{A} \beta$ production in primary neurons from APP transgenic mice (Hoe et al., 2006).

\section{APP and Reelin promote neurite outgrowth in vitro}

Reelin and APP have both been shown to promote neurite outgrowth in neuronal cultures (Qiu et al., 1995; Ohsawa et al., 1997; Niu et al., 2004). To measure the effects of Reelin on neurite outgrowth in our system, we cultured hippocampal neurons at 
A
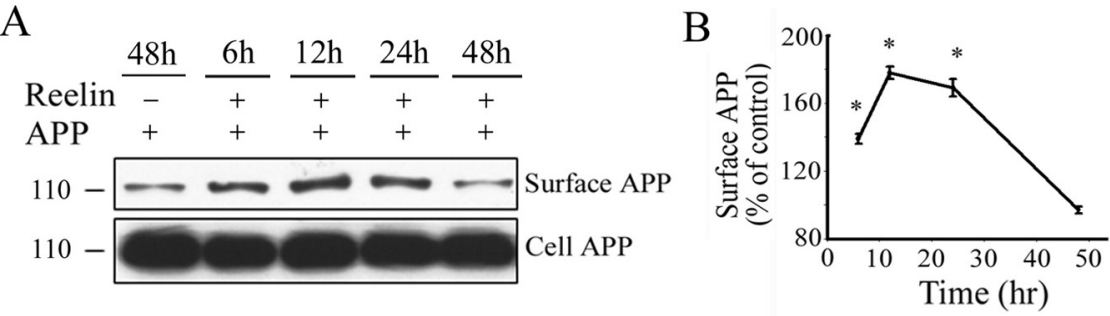

$\mathrm{C}$

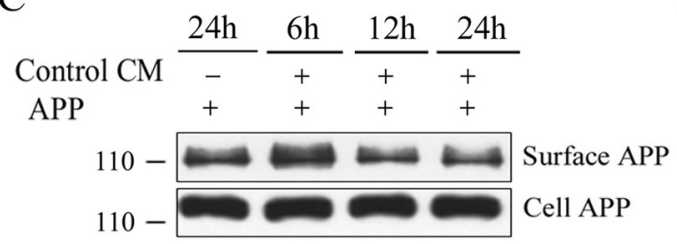

$\mathrm{D}$

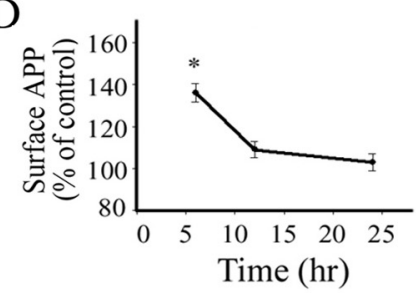

E

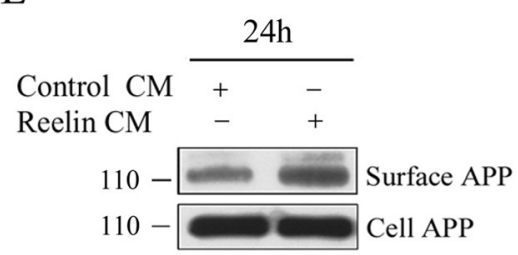

F
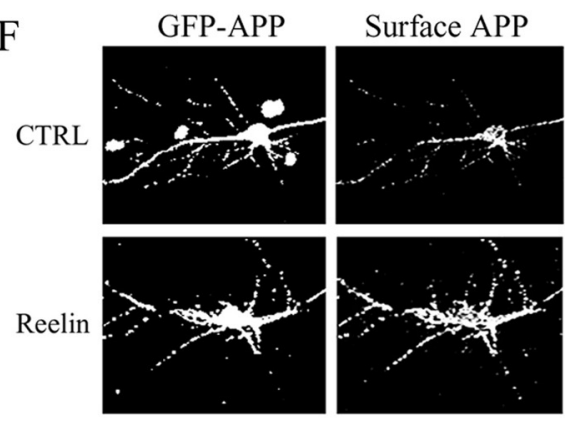

G

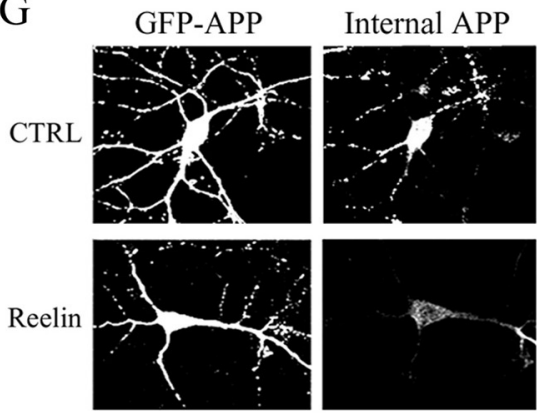

$\mathrm{H}$

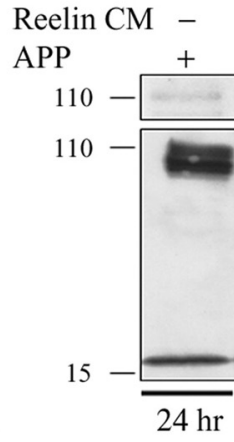

$+$

$+$
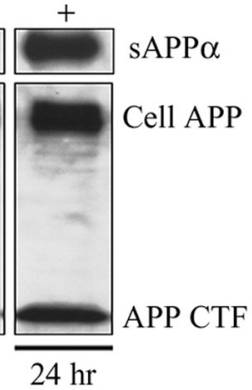

Figure 3. Reelin regulates APP trafficking and processing. A, COS7 cells expressing APP were treated with Reelin-containing medium for indicated times $(6,12,24$, or $48 \mathrm{~h})$. Cell surface proteins were biotinylated, isolated with avidin-conjugated beads, and immunoblotted with $6 \mathrm{E} 10$ antibody against APP. Total APP in cell lysates were measured in the bottom panel. $\boldsymbol{B}$, Quantification of surface APP by Reelin in COS7 cells. Cell surface APP levels significantly increased after 6, 12, and $24 \mathrm{~h}$ of Reelin treatment $(n=3$; by $39,77,69 \%$; $\left.^{*} p<0.05\right)$. C, COS7 cells expressing APP were treated with control conditioned medium for indicated times $(6,12$, or 24). Cell surface proteins were biotinylated, isolated with avidin-conjugated beads, and immunoblotted with $6 \mathrm{E} 10$ antibody against APP. Total APP in cell lysates were measured in the bottom panel. Error bars indicate SEM. D, Quantification of surface APP by control conditioned medium in COS7 cells. Cell surface APP levels were significantly increased after $6 \mathrm{~h}$ of control treatment ( $n=4$; by $36 \%{ }^{*} p<0.05$ ), but not at 12 or 24 h. $\boldsymbol{E}$, Cultured cortical neurons were treated with control or Reelin-containing medium for $24 \mathrm{~h}$ and analyzed for surface APP as in $\boldsymbol{A}$. Cell surface proteins were labeled with biotin, isolated with avidinconjugated beads, and immunoblotted with 22C11 antibody against APP. F, Cultured hippocampal neurons were transfected at DIV 12 with GFP-APP, treated with Reelin for $24 \mathrm{~h}$, and stained with an antibody recognizing the $\mathrm{N}$ terminus of APP under impermeable conditions. Left panels, GFP-APP; right panels, surface APP $(n=8-10)$. G, Neurons were transfected with GFP-APP and treated with or without Reelin-containing medium for $24 \mathrm{~h}$. After labeling cell surface APP, internalization was measured after 30 min with Alexa Fluor 555 anti-rabbit antibody (right) $(n=8-10) . \boldsymbol{H}$, COS7 cells were transfected with APP and treated with control or Reelin-containing medium for $24 \mathrm{~h}$. Secreted APP was measured in conditioned medium (15 $\mu \mathrm{l}$ ) with antibody 6E10; APP CTF was detected from cell lysates $(20 \mu \mathrm{g})$ with antibody $\mathrm{c} 1 / 6.1$.

DIV 1 with Reelin-containing medium for $24 \mathrm{~h}$. Neuronal processes were visualized using an anti-MAP2 antibody and primary neurite length was assessed by measuring the length of a neurite from the cell body to the first branch point. Reelin significantly increased primary neurite outgrowth and dendrite number (supplemental Fig. $2 A, B$, available at www.jneurosci.org as supplemental material). We also asked whether full-length APP affected dendritic neurite outgrowth. Therefore, we infected hippocampal neurons with lentiviral vectors containing GFP, APP, or shRNA against APP. APP overexpression significantly increased neurite outgrowth compared with GFP, and APP shRNA significantly decreased neurite outgrowth (supplemental Fig. 2C, available at www. jneurosci.org as supplemental material).

We then sought to determine whether the interaction between Reelin and APP was important for dendritic neurite outgrowth. We infected hippocampal neurons with GFP or APP lentivirus at DIV 1, and treated the cells with Reelin for $24 \mathrm{~h}$ at DIV 2 (Fig. 4A). Using Sholl analysis, we measured dendritic complexity at incremental lengths from the soma. We also measured the neurite length, which included the actual primary and secondary dendritic lengths (noted as neurite length) (Fig. $4 D, E$ ). We found that treatment with Reelin or overexpression of APP alone increased the complexity and length of dendrites compared with controls (neurons infected with GFP) (Fig. 4B,D,E). Reelin combined with overexpression of APP further increased dendritic neurite complexity and length (Fig. $4 B, D$ ).

We also infected hippocampal neurons with GFP or APP shRNA at DIV 1 and treated with control conditioned media or Reelin for $24 \mathrm{~h}$. Reelin treatment in GFPinfected neurons promoted neurite complexity and length consistent with Figure $4 B$. Knockdown of endogenous APP significantly reduced dendritic length but not complexity compared with GFP control (Fig. 4C,E). However, APP knockdown prevented the effect of Reelin on neurite outgrowth (Fig. 4C,E). These data support the hypothesis that a Reelin-APP interaction is critical for induction of dendritic neurite outgrowth in primary hippocampal neurons.

To test the specificity of the effect of the APP knockdown, we performed a rescue experiment (Alvarez et al., 2006). We confirmed that the APP shRNA based on the rat APP sequence differed from the human APP sequence in 4 of $21 \mathrm{nt}$. Then, we conducted rescue experiments by infecting GFP, human APP, APP (rat) shRNA, or APP and APP shRNA together in primary cortical neurons and immunoblotting with c1/6.1. APP knockdown did not inhibit human APP expression in primary cortical neurons, consistent with previous findings (Young-Pearse et al., 2007) (Fig. 4F). We then measured the effects of APP on neurite 
A
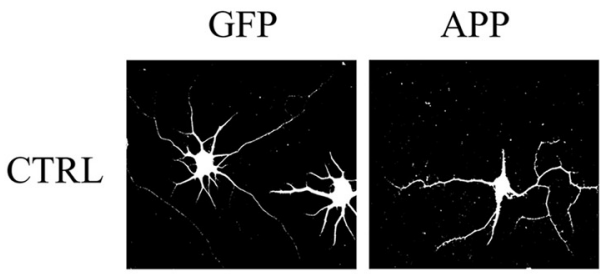
APP ShRNA

Reelin

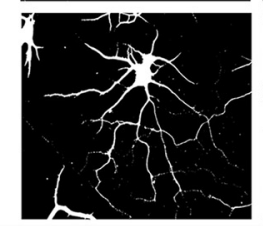

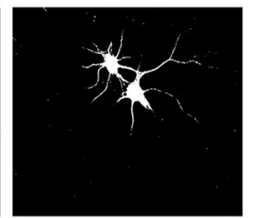

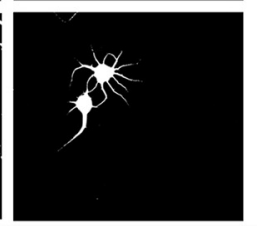

F

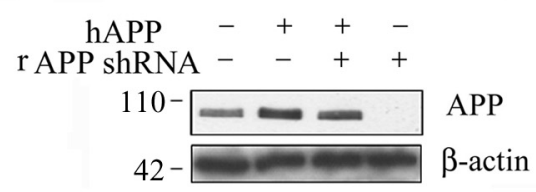

G

CTRL

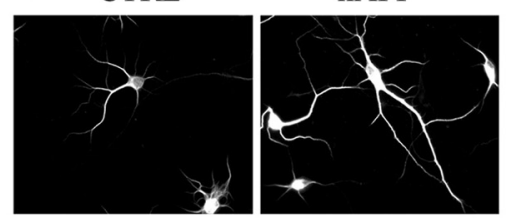

hAPP+rAPP shRNA rAPP shRNA

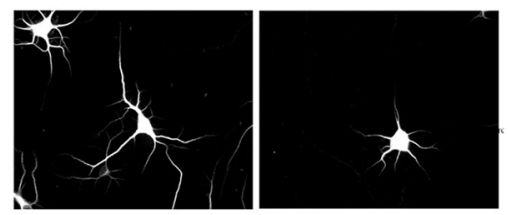

$\mathrm{H}$

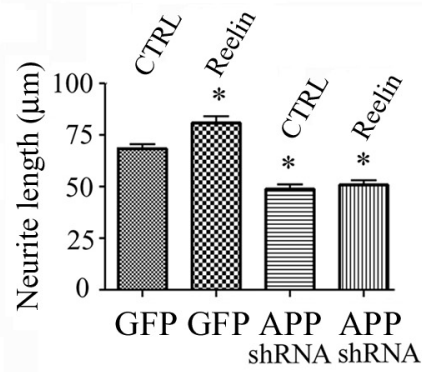

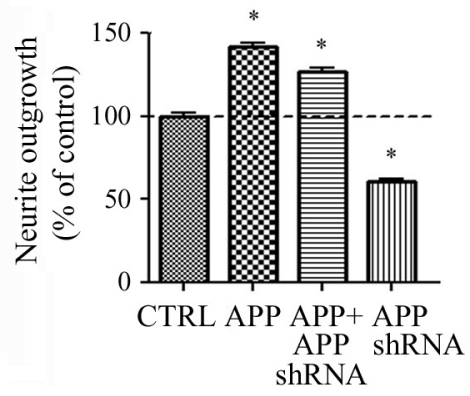

Figure 4. Interaction of APP with Reelin promotes neurite outgrowth. $A$, Neurons were infected with lentiviral constructs expressing GFP, human APP, or rat APP shRNA. After $24 \mathrm{~h}$, cells were treated with control (top panels; $n=240, n=191, n=167$ ) or Reelin (bottom panels; $n=218, n=199, n=199$ ) and imaged after $24 \mathrm{~h}$. $\boldsymbol{B}, \boldsymbol{C}$, Using Scholl analysis of cells in $\boldsymbol{A}$, we graphed the average intersections per shell per neuron against the distance from the soma (in micrometers). $\boldsymbol{D}, \boldsymbol{E}$, The average actual neurite length for primary and secondary dendrites for each group from $\boldsymbol{A}$. Results were pooled from 3 to 10 sets of cultures, and each culture included 20 random fields containing $5-8$ cells/field. ${ }^{*} p<0.05$. Error bars indicate SEM. $F$, Primary cortical neurons were infected with GFP, APP, APP shRNA, or APP and APP shRNA together and immunoblotted with c1/6.1, which recognizes both rat and human APP. shAPP only decreased rat APP levels (lane 4) but did not reduce human APP levels (lane 3). G, Neurons were infected with GFP $(n=87)$, APP $(n=69)$, APP shRNA $(n=55)$, or APP and APP shRNA together $(n=91)$, and then neurite lengths were

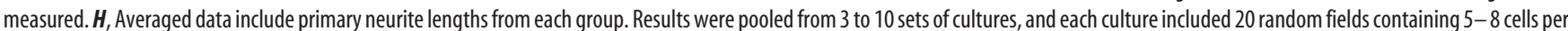
field. ${ }^{*} p<0.05$.

lengths. Consistent with our previous findings, overexpression of APP promoted neurite outgrowth (by 42\%), whereas APP shRNA decreased neurite outgrowth (39\%) (Fig. 4G,H). Human APP rescued the effect of knockdown of the rat APP (Fig. $4 G, H$ ), resulting in a significant $27 \%$ increase in neurite outgrowth.

\section{APP and Reelin promote dendritic arborization in vivo}

Overexpression of APP increased neurite outgrowth, whereas APP knockdown decreased neurite outgrowth in cultured hippocampal neurons (Fig. 4). We tested whether these results were supported by in vivo studies. We conducted Golgi staining of APP transgenic mice (4 weeks of age; at this age, the APP transgenic mice do not have A $\beta$ accumulation) (Hsiao et al., 1995), APP knock-out mice (4 weeks of age), and Reeler mice (3 weeks of age), as well as littermate controls for each line. Using pyramidal cells in cortical layers II/III, we measured the number of primary dendrites originating from the cell body, secondary dendrites that bifurcated from the primary dendrite, and dendrite length. Compared with their wild-type littermates, APP transgenic mice had significantly increased numbers of primary $(n=23 ; 6.91 \pm$ 0.22 vs $5.50 \pm 0.20$; mean $\pm \operatorname{SEM} ; p<0.001)$ and secondary $(n=$ $23 ; 16.81 \pm 0.56$ vs $13.17 \pm 0.46$; mean \pm SEM; $p<0.001)$ dendrites (Fig. $5 G, H$ ), as well as increased neurite length from the apical shaft $(n=23 ; 110.20 \pm 6.21 \mu \mathrm{m}$ vs $85.64 \pm 6.97 \mu \mathrm{m}$; mean \pm SEM; $p<0.01)$ and basal dendrites $(n=23 ; 25.68 \pm 1.57$ vs $18.99 \pm 1.67 \mu \mathrm{m}$; mean \pm SEM; $p<0.01$ ) (Fig. $5 E, F)$. In contrast, APP knock-out mice had significantly decreased numbers of primary $(n=23 ; 5.08 \pm 0.14$ vs $5.81 \pm 0.20$; mean \pm SEM; $p<0.01)$ and secondary $(n=23 ; 11.36 \pm 0.41$ vs $13.70 \pm 0.48$; mean \pm SEM; $p<0.01$ ) dendrites (Fig. $5 G, H$ ), and decreased 

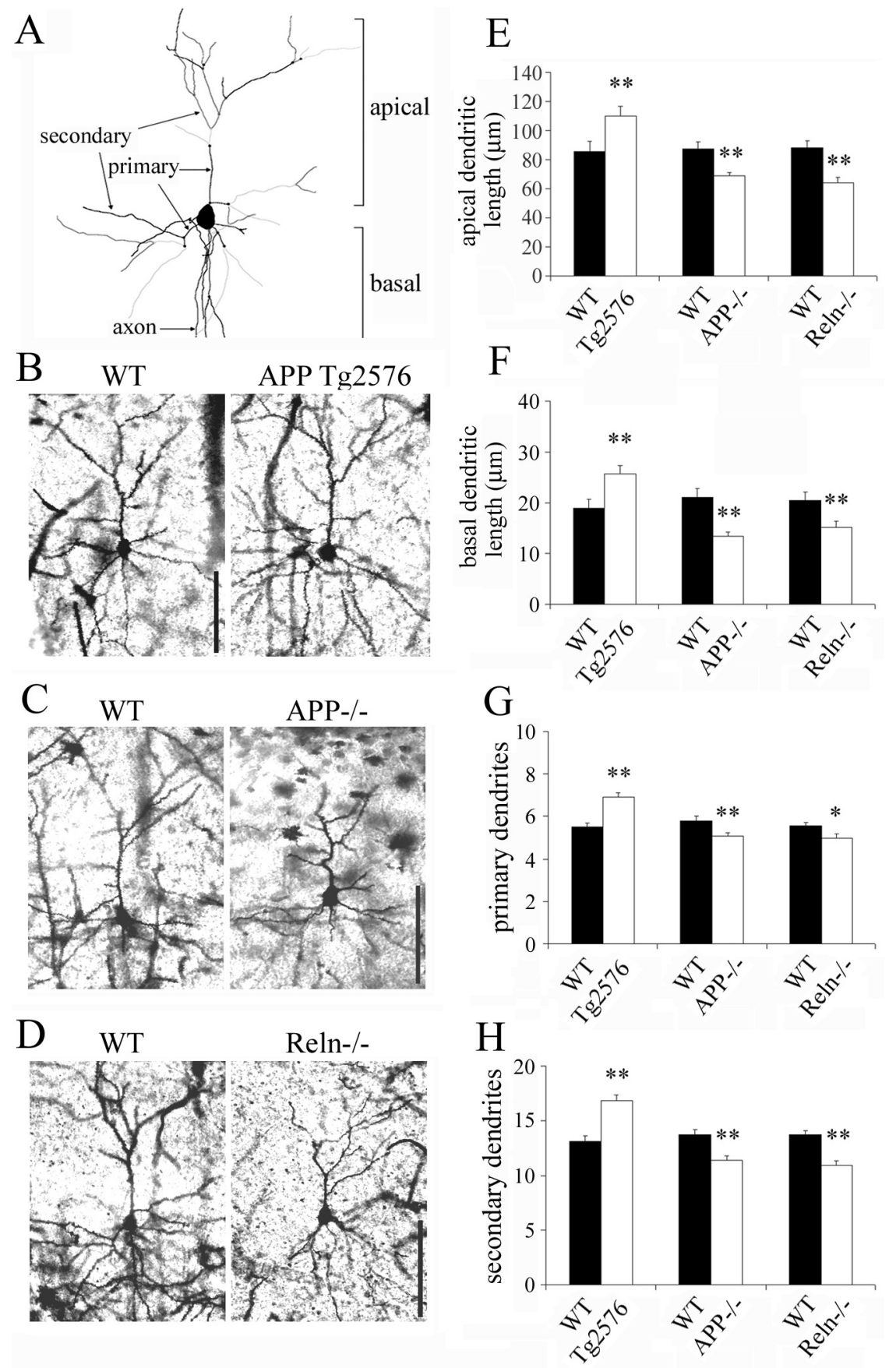

Figure 5. Dendritic numbers and lengths are increased in APP transgenic mice and decreased in APP knock-out and Reeler mice. Mouse brains were Golgi stained and cortical neurons (layers II/III) imaged. A, Three-dimensional graphical tracing representing dendrite morphology. The numbers of primary and secondary dendrites were counted; the lengths of apical and basal dendrites were measured in micrometers. $\boldsymbol{B}-\boldsymbol{D}$, Representative Golgi impregnations for each condition. Scale bar, $100 \mu \mathrm{m}$. $\boldsymbol{E}_{\boldsymbol{i}}$ Averaged data include apical dendritic length from 3- to 4-week-old wild type, APP Tg2576, APP knock-out, and Reeler knock-out mice, analyzing 23-25 neurons from each. Error bars indicate SEM. $\boldsymbol{F}$, Averaged data include basal dendritic length from each group, analyzing 23-25 neurons. $\mathbf{G}$, Averaged data include number of primary dendrites from each group, analyzing 23-25 neurons. $\boldsymbol{H}$, Averaged data include number of secondary dendrites from each group, analyzing $23-25$ neurons. ${ }^{*} p<0.05 ;{ }^{* *} p<$ 0.01 .

neurite length from the apical shaft $(n=23 ; 69.02 \pm 2.23$ vs $87.65 \pm 4.53 \mu \mathrm{m}$; mean $\pm \mathrm{SEM} ; p<0.01)$ and basal dendrites $(n=23 ; 13.39 \pm 0.81$ vs $21.08 \pm 1.69 \mu \mathrm{m}$; mean \pm SEM; $p<$ 0.01 ) compared with wild-type mice (Fig. $5 E, F$ ). In addition, we found that Reeler mice had significantly decreased numbers of primary $(n=25 ; 5.00 \pm 0.19$ vs $5.58 \pm 0.14 ;$ mean \pm SEM; $p<$
$0.05)$ and secondary $(n=25 ; 10.91 \pm 0.42$ vs $13.74 \pm 0.35$; mean \pm SEM; $p<0.01)$ dendrites (Fig. 5G,H) and decreased neurite length from the apical shaft $(n=23$; $64.39 \pm 3.12$ vs $88.08 \pm 5.25 \mu \mathrm{m}$; mean \pm SEM; $p<0.01)$ and basal dendrites $(n=$ $23 ; 15.18 \pm 1.20$ vs $20.466 \pm 1.62 \mu \mathrm{m}$; mean \pm SEM; $p<0.01)$ compared with control littermates (Fig. $5 E, F$ ). Importantly, there were no significant differences in any of these measurements between the three groups of control mice. These data demonstrate that APP and Reelin are important for neurite complexity in vivo.

\section{APP interacts with $\alpha 3$ and $\beta 1$ integrin}

Neurite outgrowth and actin reorganization are both dependent on cell surface integrins (Wei et al., 2001; Demali et al., 2006). APP colocalizes with $\beta 1$ integrin in growth cones (Yamazaki et al., 1997). To confirm that APP colocalizes with $\beta 1$ integrin in primary hippocampal neurons, we immunostained primary neurons at DIV 5 with antibodies against APP and $\beta 1$ integrin. APP immunoreactivity was strong in all neurons and showed a punctate pattern through the neuronal processes (Fig. 6A). Similarly, $\beta 1$ integrin was present in cell bodies and expressed in a punctate pattern throughout the neuronal processes that colocalized with APP (Fig. 6A, top panel). We also tested whether APP colocalized with $\alpha 3$ integrin, an integrin that commonly associates with $\beta 1$ integrin. In these hippocampal neurons, APP also colocalized with $\alpha 3$ integrin (Fig. 6A, bottom panel).

Next, we conducted biochemical fractionation of brain samples to determine whether APP, $\alpha 3$ integrin, and $\beta 1$ integrin have overlapping subcellular distributions. For these experiments, we homogenized adult mouse forebrains and separated presynaptic fractions containing synaptic vesicles (SVs) (marked by the presence of synaptophysin) from postsynaptic densities (PSDs) (marked by PSD95). We observed APP, $\alpha 3$ integrin, and $\beta 1$ integrin in both presynaptic and postsynaptic fractions (Fig. 6B).

To examine whether native integrin subunits interacted with APP in vivo, we performed coimmunoprecipitations using mouse brain lysates. We incubated brain lysates with APP antibody or IgG (as a control), and probed the precipitates with Reelin, $\alpha 3$ integrin, $\beta 1$ integrin, $\alpha \mathrm{M}$ integrin, or APP. Immunoprecipitation of APP resulted in precipitation of Reelin, $\alpha 3$ integrin, and $\beta 1$ integrin, but not $\alpha \mathrm{M}$ integrin (Fig. $6 \mathrm{C}$ ). These data show that APP and some integrin subtypes interact in the brain.

We further tested whether $\alpha 3$ or $\beta 1$ integrin levels were al- 
tered by APP in vivo. We performed Western blot analysis of $\alpha 3$ and $\beta 1$ integrin in brain lysates from APP single knock-out mice and APP-overexpressing mice (Tg2576). The levels of $\alpha 3$ and $\beta 1$ integrins were significantly increased in 1-year-old APP knock-out mice (Fig. $6 D, E)(n=3 ; 59$ and $83 \%$, respectively; $\left.{ }^{\star} p<0.05\right)$. In 1 -year-old Tg2576 mice, the level of $\alpha 3$ integrin was not altered compared with controls, whereas the level of $\beta 1$ integrin was significantly decreased by $48 \%$ (Fig. $6 F, G)\left(n=3 ;{ }^{*} p<0.01\right)$. These findings support our hypothesis that APP and $\beta 1$ integrin may interact in the brain.

\section{Reelin increased coprecipitation of APP} and $\beta 1$ integrin in primary neurons

As Reelin repeats 1 and 2 interact with $\beta 1$ integrin (Dulabon et al., 2000; Schmid et al., 2005) and Reelin repeats 3-6 interact with APP (Fig. 2C), we hypothesized that Reelin may form an extracellular link between APP and $\beta 1$ integrin. To look for an APP-Reelin- $\beta 1$ integrin complex, we treated primary neuronal cells with control or Reelin-containing medium for $24 \mathrm{~h}$. We immunoprecipitated with anti- $\beta 1$ integrin and probed for APP. Under control conditions, $\beta 1$ integrin and APP coprecipitate (Fig. $7 A$, left panel, lane $1)$. Reelin increased coprecipitation between APP and $\beta 1$ integrin (Fig. $7 A$, left panel, lane 2). Conversely, we also immunoprecipitated with anti-APP and probed for $\beta 1$ integrin. Again, we found that Reelin increased coprecipitation between APP and $\beta 1$ integrin (Fig. $7 A$, right panel, lane 2 ). These data suggest that Reelin can form an extracellular link of APP with $\beta 1$ integrin.

Given the interaction between APP and $\beta 1$ integrin, we subsequently tested whether $\beta 1$ integrin could affect the trafficking and processing of APP. We transfected COS7 cells with APP and vector or APP and $\beta 1$ integrin, and we treated cells with control or Reelin-containing medium for $24 \mathrm{~h}$. Cell surface proteins were biotin labeled, isolated with avidin beads, and immunoblotted for APP. We observed that $\beta 1$ integrin increased cell surface levels of APP (Fig. 7B, first panel). The addition of Reelin led to a greater increase in cell surface levels of APP in the presence of $\beta 1$ integrin (Fig. $7 B$, first panel). Reelin also increased the surface levels of $\beta 1$ integrin (Fig. 7B, third panel). Quantification of Figure $7 B$ demonstrated that cell surface levels of APP were significantly increased when COS7 cells were cotransfected with $\beta 1$ integrin and further by cotreatment with Reelin (Fig. 7C).

We hypothesized that the increase in surface levels of APP by $\beta 1$ integrin and Reelin might reflect a decrease in internalization

A $\alpha 3$ integrin was unaltered.
APP

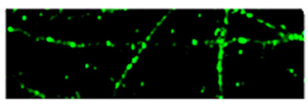

APP

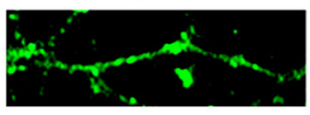

$\mathrm{B}$

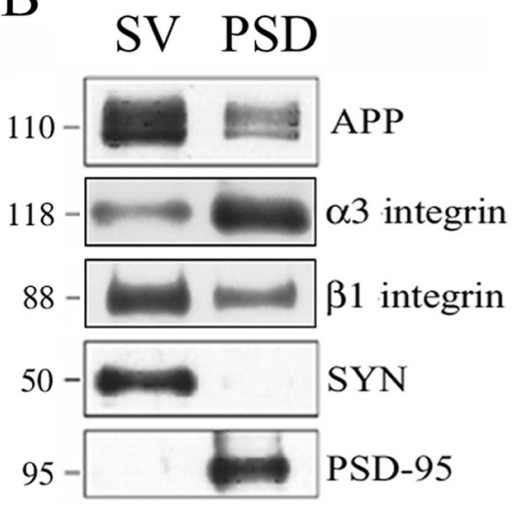

$\beta 1$ integrin

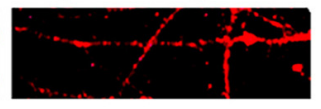

$\alpha 3$ integrin

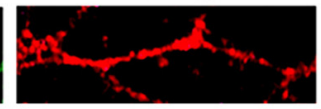

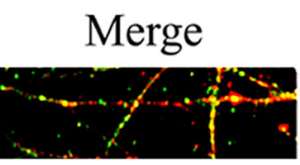

Merge

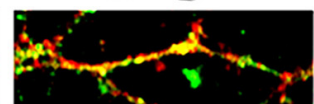

D

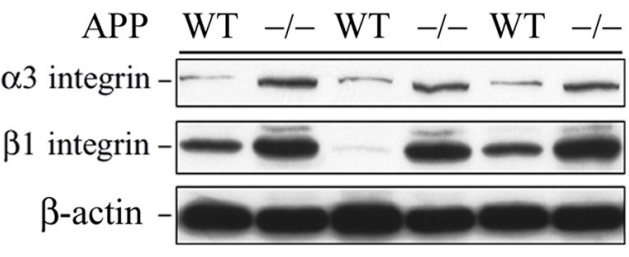

F

APP WT Tg WT Tg WT $\mathrm{Tg}$

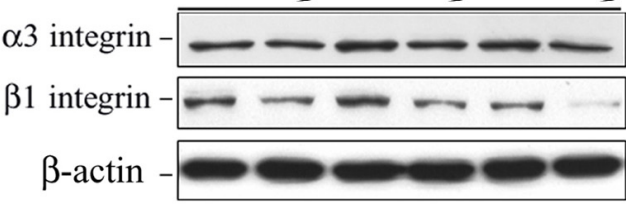

C
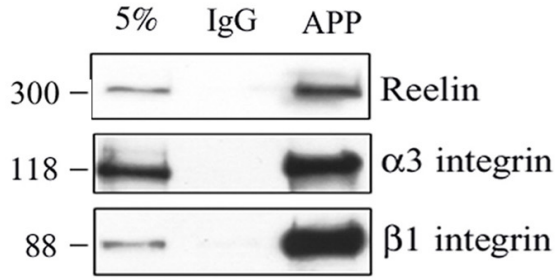

$150-\propto \alpha \mathrm{M}$ integrin

$110-\square$ APP
$\mathrm{E}$

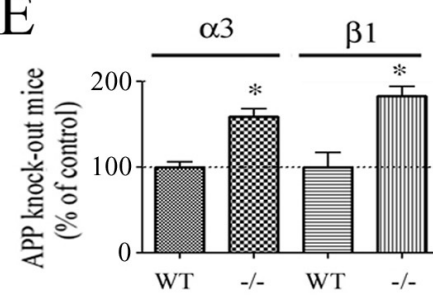

$\mathrm{G}$

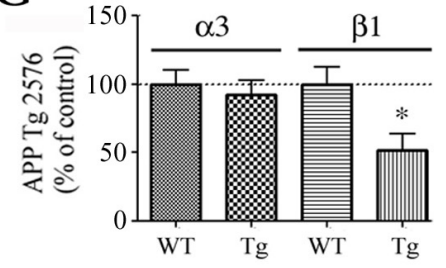

Figure 6. APP interacts with $\alpha 3$ and $\beta 1$ integrin. $\boldsymbol{A}$, Primary cortical neurons were fixed and immunostained at DIV 5 with c1/6.1 and anti- $\beta 1$ or anti- $\alpha 3$ antibody. The antibodies were detected with Alexa Fluor 488 anti-mouse antibody (left panel) and Alexa Fluor 594 anti-rabbit antibody (middle panel). The neurons were observed under a confocal laser-scanning microscope $(40 \times)$. Colocalization of APP and $\beta 1$ integrin or $\alpha 3$ integrin is shown in the right panel. $\boldsymbol{B}$, We performed immunoblot analysis of APP, $\alpha 3$ integrin, $\beta 1$ integrin, synaptophysin, and PSD-95 in presynaptic vesicles (SV) and postsynaptic density (PSD) fractions. APP, $\alpha 3$ integrin, and $\beta 1$ integrin were present in the presynaptic and postsynaptic fractions; PSD-95 was present in the postsynaptic fractions; synaptophysin was present presynaptically. C, Mouse brain lysates (300 $\mu \mathrm{g}$ ) were immunoprecipitated with c1/6.1 and probed with G10, $\alpha 3$ integrin, $\beta 1$ integrin, $\alpha$ M integrin, and APP. Interaction of APP with Reelin, $\alpha 3$ integrin, and $\beta 1$ integrin was detected. $\boldsymbol{D}$, Levels of $\alpha 3$ and $\beta 1$ integrin were measured by Western blot analysis with $\alpha 3$ or $\beta 1$ integrin antibody and compared between APP-deficient mice $(n=3)$ and wild-type mice $(n=3)$. $\boldsymbol{E}$, Quantification of the levels of $\alpha 3$ and $\beta 1$ integrins shown in $\boldsymbol{D}$, demonstrating that both $\alpha 3$ and $\beta 1$ integrins were significantly increased in APP knock-out mice, respectively ( $n=3$; by 59 and by $83 \%$; ${ }^{*} p<0.05$ ). Error bars indicate SEM. $\boldsymbol{F}$, Protein levels of $\alpha 3$ and $\beta 1$ integrins were analyzed and compared between APP Tg2576 mice $(n=3)$ and wild-type controls $(n=3)$. G, Quantification of the levels of $\alpha 3$ or $\beta 1$ integrin shown in $\boldsymbol{F}$, demonstrating that $\beta 1$ integrin was significantly decreased in APP Tg2576 mice $\left(n=3\right.$; by $48 \%$; ${ }^{*} p<0.01$ ) but that of APP. To test this hypothesis, we transfected hippocampal neurons with APP and vector or APP and $\beta 1$ integrin and treated them with control or Reelin-containing medium. $\beta 1$ integrin alone or $\beta 1$ integrin combined with Reelin significantly de- 
A

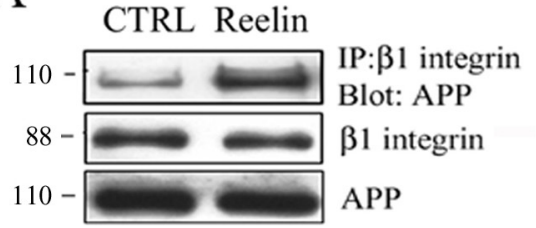

B

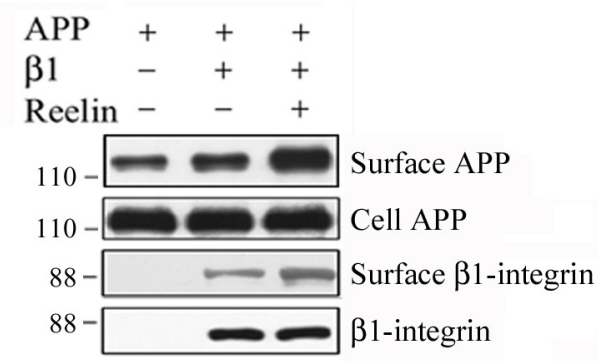

D

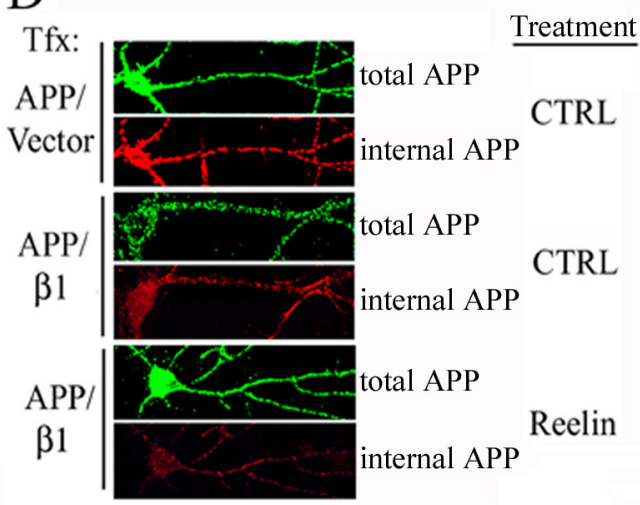

F

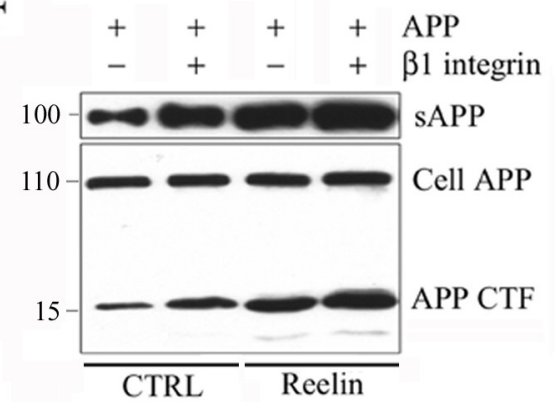

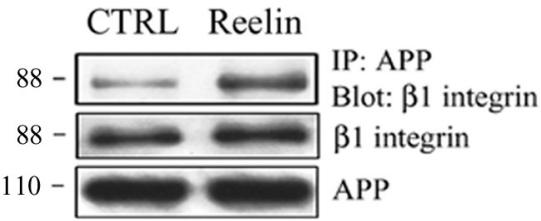

C

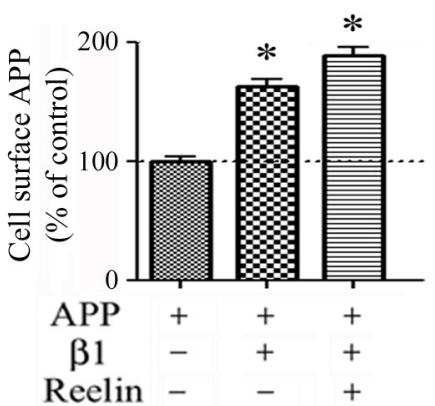

E

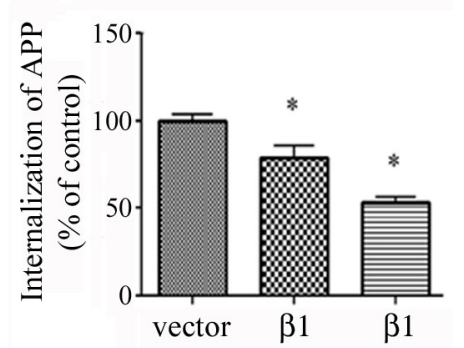

(CTRL) (CTRL) (Reelin)

creased internalization of APP (Fig. 7D, sixth panel). Quantitative analysis showed significant 29 and $47 \%$ decreases in APP internalization by $\beta 1$ integrin or $\beta 1$ integrin combined with Reelin (Fig. 7E), respectively.

Next, we tested whether $\beta 1$ integrin or $\beta 1$ integrin combined with Reelin affected APP processing in COS7 cells. Secreted APP was measured in conditioned medium, and fulllength APP or APP CTF was assayed in cell lysates. Cotransfection with $\beta 1$ integrin increased secreted APP and APP CTF (Fig. 7F, lane 2). Reelin alone increased the levels of APP proteolytic fragments (Fig. 7F, lane 3), and Reelin and $\beta 1$ integrin together further increased them (Fig. $7 F$, lane 4).

The effect of Reelin and APP on neurite outgrowth requires integrins

$\alpha 3 \beta 1$ integrin is an important component of neurite outgrowth (Mechai et al., 2005). We tested whether the interactions of Reelin or APP with $\alpha 3 \beta 1$ integrin affected dendritic neurite outgrowth in vitro. For these experiments, we infected cultures of hippocampal neurons with lentivirus expressing GFP or APP at DIV 1 and treated them with blocking antibodies to integrin or Reelin-containing medium. APP increased dendritic outgrowth (Fig. $8 A$ ), consistent with our previous finding (Fig. $4)$. The $\alpha 3 \beta 1$ integrin antibody decreased neurite outgrowth and, importantly, prevented the effect of APP on neurite outgrowth (Fig. 8 A). Reelin (as above) (Fig. 4) promoted neurite outgrowth (Fig. $8 B$ ). The presence of the $\alpha 3 \beta 1$ integrin antibody significantly decreased neurite outgrowth and prevented the effect of Reelin on neurite outgrowth (Fig. $8 B$ ). The $\alpha 5 \beta 1$ integrin antibody had no effect on either basal neurite outgrowth or outgrowth induced by Reelin. Together, these data demonstrate that Reelin $-\alpha 3 \beta 1$ integrin or $\mathrm{APP}-\alpha 3 \beta 1$ integrin interactions have a potential role for induction of dendritic neurite outgrowth of neurons in culture.

Figure 7. Reelin increases coprecipitation between APP and $\beta 1$ integrin in primary neurons. $A$, Primary neuronal lysates (1 $\mathrm{mg}$ ) were treated with control or Reelin-containing medium for $24 \mathrm{~h}$ and immunoprecipitated with a $\beta 1$ integrin antibody and probed with c1/6.1 antibody (left panel). Inversely, primary neurons (1 mg) were immunoprecipitated with $\mathrm{c} 1 / 6.1$ and probed with anti- $\beta 1$ integrin antibody (right panel). $\boldsymbol{B}, \operatorname{COS} 7$ cells expressing APP or both APP and $\beta 1$ integrin were treated with control or Reelin-containing medium for $24 \mathrm{~h}$. Cell surface proteins were labeled with biotin, isolated with avidin beads, and immunoblotted with 6 E10 for APP and anti-HA for $\beta 1$ integrin $(n=3)$. C, Quantification of surface APP by Reelin in the presence of $\beta 1$ integrin in COS7 cells. Cell surface levels of APP were significantly increased when COS7 cells were cotransfected with $\beta 1$ integrin $\left(n=5\right.$; by $63 \%$; $\left.{ }^{*} p<0.05\right)$ and further by cotreatment with Reelin $\left(n=5\right.$; by $89 \%$; $\left.{ }^{*} p<0.05\right)$. Error bars indicate SEM. $\boldsymbol{D}$, Primary hippocampal neurons were transfected with GFP-APP and vector or GFP-APP and $\beta 1$ integrin and treated with control or Reelin-containing medium for $24 \mathrm{~h}$. Internalized APP was labeled after 30 min with Alexa Fluor 555 anti-rabbit antibody. $\boldsymbol{E}$, Quantitative analysis showed significant $29 \%\left({ }^{*} p<0.05 ; n=6\right)$ and $47 \%\left({ }^{*} p<0.01 ; n=6\right)$ decreases in APP internalization by $\beta 1$ integrin or $\beta 1$ integrin combined with Reelin, respectively. $F$, COS7 cells were transfected with APP and vector or APP and $\beta 1$ integrin and treated with control or Reelin-containing medium for $24 \mathrm{~h}$. Secreted APP was measured in conditioned media (15 $\mu l$ ) with antibody 6E10; APP (TF was detected from cell lysates $(20 \mu \mathrm{g})$ with antibody $\mathrm{c} 1 / 6.1(n=3)$. Reelin alone increased APP proteolytic fragments, and Reelin and $\beta 1$ integrin together further increased them.

\section{Discussion}

In this study, we demonstrate that Reelin interacts with APP and affects its trafficking and processing. Based on our findings regarding $\mathrm{APP}-$ integrin interactions, we hypothesize that the complex of APP and Reelin could form an extracellular link between APP and $\alpha 3 \beta 1$ integrin (Fig. $8 C$, diagram). In addition, we observed that these molecules contribute to the structure of neuronal processes in vitro, with supporting data in vivo from several lines of knock-out and transgenic mice. 


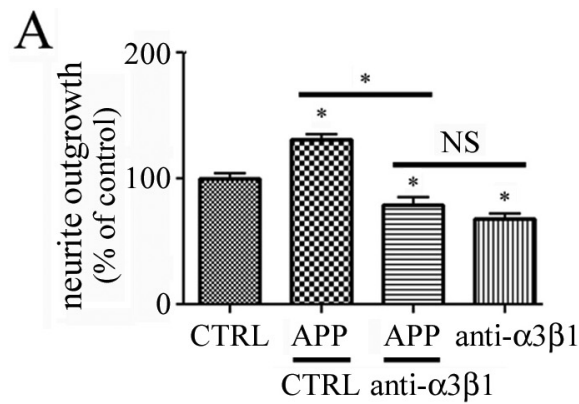

$\mathrm{B}$
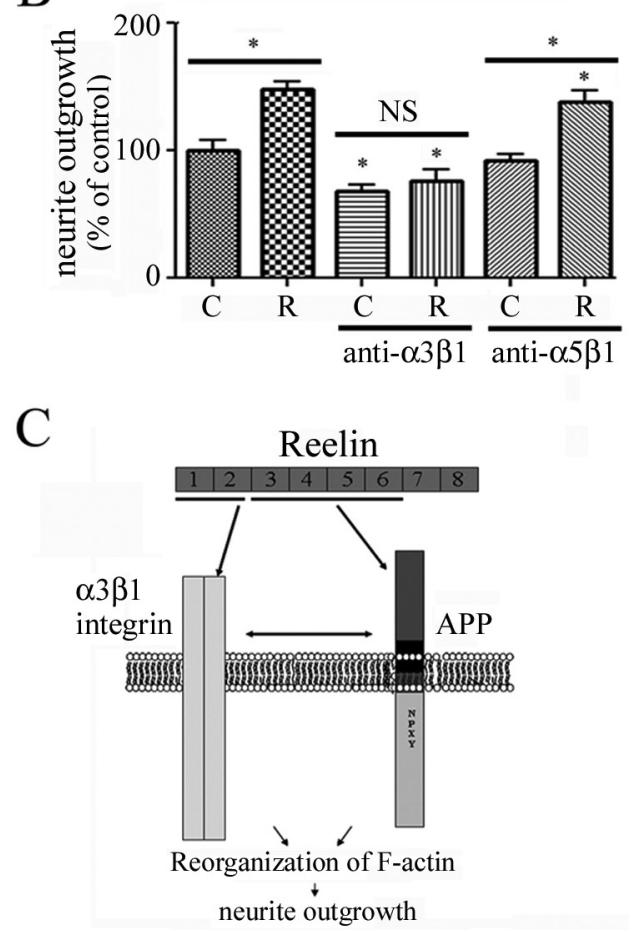

Figure 8. The effect of Reelin and APP on neurite outgrowth requires integrins. A, Hippocampal neurons were infected with lentiviral vectors expressing GFP $(n=163)$ or APP $(n=$ 201) and treated with $\alpha 3 \beta 1$ antibody $(n=193)$. Average length of total dendrites was quantified. Results were pooled from 3 to 10 sets of cultures. Twenty random fields containing $5-8$ neurons per field were taken from each culture $\left({ }^{*} p<0.05\right)$. Error bars indicate SEM. $\boldsymbol{B}$, Neurons were incubated in control $(n=100)$ or Reelin-containing medium $(n=100)$ and either anti$\alpha 3 \beta 1$ antibody (control, $n=203$; Reelin, $n=203$ ) or anti- $\alpha 5 \beta 1$ antibody (control, $n=199$; Reelin, $n=208$ ) was added to the media. The length of dendritic neurites was quantified. The presence of the $\alpha 3 \beta 1$ integrin antibody significantly decreased neurite outgrowth and prevented the effect of Reelin on neurite outgrowth. C, A model of APP, Reelin, and $\alpha 3 \beta 1$ integrin interactions. Reelin repeats 1 and 2 interact with $\alpha 3 \beta 1$ integrin subunits, and the Reelin 3-6 domain interacts with APP E1 domain. The Reelin- $\alpha 3 \beta 1$ integrin and integrin-APP interaction may lead to reorganization of the cytoskeleton, or it may stabilize the actin cytoskeleton by inducing $\mathrm{n}$-cofilin phosphorylation.

\section{APP interactions with Reelin}

The interaction between Reelin and APP was demonstrated in this study by a number of independent techniques. APP and Reelin coprecipitated in brain lysates, primary neurons, and transfected cells (these latter assays allowed us to define specific interacting domains of APP and Reelin). Extracellular Reelin altered APP trafficking and processing in a number of independent assays, including cell surface biotinylation studies, live-cell staining, Western blot analysis of APP proteolytic fragments, and A $\beta$ ELISA. In vivo, APP and Reelin demonstrate similar regulation through brain development, with both peaking early in postnatal development. From these data, we propose that Reelin is another extracellular matrix protein that can be a ligand for APP.

Studies in several systems have suggested that APP and Reelin may be functionally related. Overexpression of APP interferes with the effects of Reelin on Dab1 phosphorylation in cortical neurons in Drosophila (Pramatarova et al., 2006), and Reelin affects the trafficking and proteolysis of APP in cells in culture (Hoe et al., 2006). The CNS phenotypes of Dab1 hypomorphism in mice are altered by increasing and reducing expression of APP, suggesting that APP may be involved in the Reelin signaling pathway (Pramatarova et al., 2008). Reelin and Dab1 knock-out mice have increased levels of tau phosphorylation (Hiesberger et al., 1999), and quantitative trait locus (QTL) analysis was conducted in Dab1 knock out mice to further determine the effect of Dab1 on tau phosphorylation. These studies found that one of the QTL regions (chromosome 16) (60 centimorgans) includes APP, and the authors suggested that Reelin signaling may involve APP (Brich et al., 2003). An effect of APP on Reelin signaling was also demonstrated by a study finding that the APP C-terminal domain prevented the inhibition of neuritogenesis by Reelin (Hoareau et al., 2008), although another study did show an opposing effect of Reelin on neurite outgrowth (Niu et al., 2004). In this study, we found that mice with increased or decreased levels of APP demonstrated compensatory changes in Reelin levels, consistent with previous findings that the number of Reelin-expressing neurons was decreased in transgenic APP mice (Botella-López et al., 2006; Chin et al., 2007). Together, these studies support the idea that APP and Reelin functionally interact in vitro and in vivo.

\section{Effect of Reelin and $\beta 1$ integrin on APP trafficking and processing}

Cleavages of APP are altered by interactions with extracellular ligands. We and others have found that F-spondin, an ECM protein, interacted with APP (Ho and Südhof, 2004; Hoe et al., 2005) and increased cell surface levels of APP (Hoe et al., 2005). The interaction of F-spondin with APP led to increased $\alpha$-cleavage and decreased $\beta$-cleavage of APP (Ho and Südhof, 2004; Hoe et al., 2005). F-spondin interacted with the E2 domain of APP (Ho and Südhof, 2004), whereas we found that Reelin interacted with the E1 domain of APP, suggesting that both interactions with APP may occur simultaneously. These interactions between the full-length form of APP bound to the cell membrane and extracellular compounds may be regulated by cleavage of APP from the cell surface. This hypothesis is further supported by our observations that Reelin inhibits endocytosis of APP from the cell surface and prevents its trafficking to endosomes where APP is cleaved by $\beta$-secretase to generate $\mathrm{A} \beta$.

The interaction between APP and $\beta 1$ integrin was first shown in growth cones at contact sites in neuronal cells (Yamazaki et al., 1997). In the present study, we demonstrate that $\beta 1$ integrin increased cell surface levels of APP and decreased internalization of APP (Fig. $7 D, E$ ), providing evidence that $\beta 1$ integrin also may regulate APP trafficking. These in vitro findings suggest that both Reelin and $\beta 1$ integrin can alter APP trafficking, perhaps through direct interactions. To test this idea, we performed an APP internalization assay in hippocampal neurons and found that $\beta 1$ integrin combined with Reelin significantly decreased internalization of APP. These results support our hypothesis that Reelin stabilizes the interaction between APP and $\beta 1$ integrin on the cell surface. We found that $\alpha 3$ integrin did not alter APP processing with or without Reelin (data not shown), although $\alpha 3$ integrin interacted with APP in brain lysates. Integrins form heterodimers of $\alpha$ and $\beta$ subunits (Chan et al., 2006); therefore, it is possible 
that APP may directly interact with $\beta 1$ integrin at first, and subsequently indirectly interact with $\alpha 3$ integrin or other $\alpha$ subunits. In this study, we did not define which domains of APP and $\beta 1$ integrin interacted.

\section{The biological effects of APP-Reelin- $\alpha 3 \beta 1$ on neurite development}

Several studies show that Reelin signaling has an important role in neuronal migration through its interaction with ApoE receptor 2 and the VLDL (very low-density lipoprotein) receptor, and the subsequent phosphorylation of Dab-1. After removal of any of these components (Reelin, receptors, or Dab-1), cortical layer formation is severely disrupted, leading to the model that these interactions are important for laminar organization in development (Hiesberger et al., 1999). However, each of these components is also present in the adult brain, and their functions there are not as well defined. In synapses, Reelin promotes tyrosine phosphorylation of NMDA receptor subunits (e.g., NR2A) and facilitates long-term potentiation (LTP) (Beffert et al., 2005). Reelin signaling has an important role in NMDA and AMPA receptor function (Qiu et al., 2006), maturation of glutamatergic synapses (Qiu and Weeber, 2007), regulation of neurite outgrowth in vitro (Niu et al., 2004), and dendritic spine density (Niu et al., 2008). Our study confirmed that Reelin knock-out mice have decreased dendrite numbers and decreased dendrite lengths compared with littermate controls, supporting a role for Reelin in dendritic complexity.

Similarly, integrins play important roles in neurite development, neuronal migration, and synapse functions. $\beta 1$ integrin facilitates reorganization of actin filaments (Wei et al., 2001; Demali et al., 2006) and affects neuronal migration (Dulabon et al., 2000) and neurite outgrowth (Niu et al., 2004; Mechai et al., 2005). The Reelin- $\alpha 3 \beta 1$ integrin interaction regulates neuronal migration (Dulabon et al., 2000), perhaps by reorganizing the actin cytoskeleton, or by stabilizing the cytoskeleton through n-cofilin phosphorylation (Chai et al., 2009). Integrins also regulate synaptic glutamate receptor function, synaptic plasticity, working memory, and LTP (Kramár et al., 2002; Chan et al., 2006). The APP- $\beta 1$ integrin interaction is also important in neurite outgrowth (Young-Pearse et al., 2008). We suggest that the functions of Reelin and $\beta 1$ integrins on these processes may be modulated by APP (or other APP family members). Our findings raise an interesting question of whether a Reelin-APP- $\alpha 3 \beta 1$ integrins interaction facilitates neuronal migration during development and synaptic plasticity in the adult brain, although additional in vivo work needs to be done to thoroughly test these ideas.

To define conditions of interaction of Reelin with the different cell surface molecules, it will be necessary to determine the binding affinities of Reelin for the apoE receptors and for APP, and determine whether these molecules compete for Reelin, or bind it cooperatively. One argument against a simple functional interaction between APP and Reelin is that APP knock-out mice do not show the dramatic neuronal migration deficits seen in mice lacking functional Reelin (Zheng et al., 1996; Andrade et al., 2007). Recently, however, several studies have shown that APP, like Reelin, has important functions in neuronal development and migration. APP promotes postdevelopmental neurite arborization through the interaction with Abelson tyrosine kinase (Leyssen et al., 2005), and neurons from APP ${ }^{-/-}$mice show impaired dendrite neurite outgrowth in vitro (Perez et al., 1997). In this study, we found that APP transgenic mice had increased dendritic complexity and length (at a young age), whereas APP knock-out mice showed decreased dendritic numbers and length. In the retinotectal system, APP interacts with contactin 4 and NgCAM (neuron-glia cell adhesion molecule), increasing retinal axon growth (Osterfield et al., 2008). Inhibition of APP in the subventricular zone in utero prevents correct neuronal migration during cortical development (Young-Pearse et al., 2007). Finally, the brains of mice lacking all three APP family members (APP, APLP1, and APLP2) demonstrate type 2 lissencephaly, indicative of a major neuronal migration defect (Herms et al., 2004). Thus, APP may have important roles in neuronal migration, and these functions may be partially redundant with functions of other APP family members.

\section{Reelin and Alzheimer's disease}

Although this work focused on the effects of Reelin on the normal functions of APP, there are also data that suggest Reelin may also be involved in pathogenic mechanisms in AD. Reelin protein and mRNA are decreased in AD brains (Botella-López et al., 2006; Chin et al., 2007) and Reelin protein is found in the plaques of double transgenic APP/PS1 mice (Wirths et al., 2001). APP is present in dystrophic neurites around amyloid plaques (Motoi et al., 2004), implying that a possible interaction between Reelin and APP contributes to an accumulation of dystrophic neurites. Finally, our findings of dendritic abnormalities in young APP transgenic mice suggest that mouse models of AD may demonstrate some behavioral problems dependent on the overexpression of APP and not on the accumulation of the $\mathrm{A} \beta$ peptide.

\section{Conclusion}

In summary, using an array of biochemical and cell biological techniques, we identified Reelin/APP/integrins interactions that are critical for regulating neurite outgrowth. Consistent with our in vitro results, we found that APP and Reelin knock-out mice have decreased dendritic complexity and length. Our finding that Reelin interacts with APP adds to work linking APP to the ECM, supporting findings about the effects of APP on neuronal migration and synaptic function. The alteration of APP trafficking and processing by extracellular ligands may contribute to the development of new therapeutic approaches for AD.

\section{References}

Alvarez VA, Ridenour DA, Sabatini BL (2006) Retraction of synapses and dendritic spines induced by off-target effects of RNA interference. J Neurosci 26:7820-7825.

Andrade N, Komnenovic V, Blake SM, Jossin Y, Howell B, Goffinet A, Schneider WJ, Nimpf J (2007) ApoER2/VLDL receptor and Dab1 in the rostral migratory stream function in postnatal neuronal migration independently of Reelin. Proc Natl Acad Sci U S A 104:8508-8513.

Andressen C, Arnhold S, Puschmann M, Bloch W, Hescheler J, Fässler R, Addicks K (1998) Betal integrin deficiency impairs migration and differentiation of mouse embryonic stem cell derived neurons. Neurosci Lett 251:165-168.

Beffert U, Weeber EJ, Durudas A, Qiu S, Masiulis I, Sweatt JD, Li WP, Adelmann G, Frotscher M, Hammer RE, Herz J (2005) Modulation of synaptic plasticity and memory by Reelin involves differential splicing of the lipoprotein receptor Apoer2. Neuron 47:567-579.

Botella-López A, Burgaya F, Gavín R, García-Ayllón MS, Gómez-Tortosa E, Peña-Casanova J, Ureña JM, Del Río JA, Blesa R, Soriano E, Sáez-Valero J (2006) Reelin expression and glycosylation patterns are altered in Alzheimer's disease. Proc Natl Acad Sci U S A 103:5573-5578.

Brich J, Shie FS, Howell BW, Li R, Tus K, Wakeland EK, Jin LW, Mumby M, Churchill G, Herz J, Cooper JA (2003) Genetic modulation of tau phosphorylation in the mouse. J Neurosci 23:187-192.

Chai X, Förster E, Zhao S, Bock HH, Frotscher M (2009) Reelin stabilizes 
the actin cytoskeleton of neuronal processes by inducing $\mathrm{n}$-cofilin phosphorylation at serine3. J Neurosci 29:288-299.

Chan CS, Weeber EJ, Zong L, Fuchs E, Sweatt JD, Davis RL (2006) $\beta 1$ integrins are required for hippocampal AMPA receptor-dependent synaptic transmission, synaptic plasticity, and working memory. J Neurosci 26:223-232.

Chen K, Ochalski PG, Tran TS, Sahir N, Schubert M, Pramatarova A, Howell BW (2004) Interaction between Dabl and CrkII is promoted by Reelin signaling. J Cell Sci 117:4527-4536.

Chin J, Massaro CM, Palop JJ, Thwin MT, Yu GQ, Bien-Ly N, Bender A, Mucke L (2007) Reelin depletion in the entorhinal cortex of human amyloid precursor protein transgenic mice and humans with Alzheimer's disease. J Neurosci 27:2727-2733.

DeFreitas MF, Yoshida CK, Frazier WA, Mendrick DL, Kypta RM, Reichardt LF (1995) Identification of integrin alpha 3 beta 1 as a neuronal thrombospondin receptor mediating neurite outgrowth. Neuron 15:333-343.

Demali KA, Jue AL, Burridge K (2006) IpaA targets betal integrins and rho to promote actin cytoskeleton rearrangements necessary for Shigella entry. J Biol Chem 281:39534-39541.

Dulabon L, Olson EC, Taglienti MG, Eisenhuth S, McGrath B, Walsh CA, Kreidberg JA, Anton ES (2000) Reelin binds alpha3betal integrin and inhibits neuronal migration. Neuron 27:33-44.

Gotthardt M, Trommsdorff M, Nevitt MF, Shelton J, Richardson JA, Stockinger W, Nimpf J, Herz J (2000) Interactions of the low density lipoprotein receptor gene family with cytosolic adaptor and scaffold proteins suggest diverse biological functions in cellular communication and signal transduction. J Biol Chem 275:25616-25624.

Herms J, Anliker B, Heber S, Ring S, Fuhrmann M, Kretzschmar H, Sisodia S, Müller U (2004) Cortical dysplasia resembling human type 2 lissencephaly in mice lacking all three APP family members. EMBO J 23:4106-4115.

Hiesberger T, Trommsdorff M, Howell BW, Goffinet A, Mumby MC, Cooper JA, Herz J (1999) Direct binding of Reelin to VLDL receptor and ApoE receptor 2 induces tyrosine phosphorylation of disabled-1 and modulates tau phosphorylation. Neuron 24:481-489.

Ho A, Südhof TC (2004) Binding of F-spondin to amyloid-beta precursor protein: a candidate amyloid-beta precursor protein ligand that modulates amyloid-beta precursor protein cleavage. Proc Natl Acad Sci U S A 101:2548-2553.

Hoareau C, Borrell V, Soriano E, Krebs MO, Prochiantz A, Allinquant B (2008) Amyloid precursor protein cytoplasmic domain antagonizes reelin neurite outgrowth inhibition of hippocampal neurons. Neurobiol Aging 29:542-553.

Hoe HS, Wessner D, Beffert U, Becker AG, Matsuoka Y, Rebeck GW (2005) F-spondin interaction with the apolipoprotein $\mathrm{E}$ receptor ApoEr2 affects processing of amyloid precursor protein. Mol Cell Biol 25:9259-9268.

Hoe HS, Tran TS, Matsuoka Y, Howell BW, Rebeck GW (2006) DAB1 and Reelin effects on amyloid precursor protein and ApoE receptor 2 trafficking and processing. J Biol Chem 281:35176-35185.

Hoe HS, Cooper MJ, Burns MP, Lewis PA, van der Brug M, Chakraborty G, Cartagena CM, Pak DT, Cookson MR, Rebeck GW (2007) The metalloprotease inhibitor TIMP-3 regulates amyloid precursor protein and apolipoprotein E receptor proteolysis. J Neurosci 27:10895-10905.

Hoogenraad CC, Milstein AD, Ethell IM, Henkemeyer M, Sheng M (2005) GRIP1 controls dendrite morphogenesis by regulating EphB receptor trafficking. Nat Neurosci 8:906-915.

Horikoshi Y, Sakaguchi G, Becker AG, Gray AJ, Duff K, Aisen PS, Yamaguchi H, Maeda M, Kinoshita N, Matsuoka Y (2004) Development of Abeta terminal end-specific antibodies and sensitive ELISA for Abeta variant. Biochem Biophys Res Commun 319:733-737.

Hsiao KK, Borchelt DR, Olson K, Johannsdottir R, Kitt C, Yunis W, Xu S, Eckman C, Younkin S, Price D, Iadecola C, Clark HB, Carlson G (1995) Age-related CNS disorder and early death in transgenic FVB/N mice overexpressing Alzheimer amyloid precursor proteins. Neuron 15:1203-1218.

Jossin Y, Bar I, Ignatova N, Tissir F, De Rouvroit CL, Goffinet AM (2003) The reelin signaling pathway: some recent developments. Cereb Cortex 13:627-633.

Kramár EA, Bernard JA, Gall CM, Lynch G (2002) Alpha3 integrin receptors contribute to the consolidation of long-term potentiation. Neuroscience 110:29-39.

Leyssen M, Ayaz D, Hébert SS, Reeve S, De Strooper B, Hassan BA (2005) Amyloid precursor protein promotes post-developmental neurite arborization in the Drosophila brain. EMBO J 24:2944-2955.

Mechai N, Wenzel M, Koch M, Lucka L, Horstkorte R, Reutter W, Danker K (2005) The cytoplasmic tail of the alpha3 integrin subunit promotes neurite outgrowth in PC12 cells. J Neurosci Res 82:753-761.

Miettinen R, Riedel A, Kalesnykas G, Kettunen HP, Puoliväli J, Soininen H, Arendt T (2005) Reelin-immunoreactivity in the hippocampal formation of 9-month-old wildtype mouse: effects of APP/PS1 genotype and ovariectomy. J Chem Neuroanat 30:105-118.

Milward EA, Papadopoulos R, Fuller SJ, Moir RD, Small D, Beyreuther K, Masters CL (1992) The amyloid protein precursor of Alzheimer's disease is a mediator of the effects of nerve growth factor on neurite outgrowth. Neuron 9:129-137.

Motoi Y, Itaya M, Mori H, Mizuno Y, Iwasaki T, Hattori H, Haga S, Ikeda K (2004) Apolipoprotein E receptor 2 is involved in neuritic plaque formation in APP sw mice. Neurosci Lett 368:144-147.

Niu S, Renfro A, Quattrocchi CC, Sheldon M, D’Arcangelo G (2004) Reelin promotes hippocampal dendrite development through the VLDLR/ ApoER2-Dab1 pathway. Neuron 41:71-84.

Niu S, Yabut O, D’Arcangelo G (2008) The Reelin signaling pathways promotes dendritic spine development in hippocampal neurons. J Neurosci 28:10339-10348.

Ohsawa I, Takamura C, Kohsaka S (1997) The amino-terminal region of amyloid precursor protein is responsible for neurite outgrowth in rat neocortical explant culture. Biochem Biophys Res Commun 236:59-65

Osterfield M, Egelund R, Young LM, Flanagan JG (2008) Interaction of amyloid precursor protein with contactins and NgCAM in the retinotectal system. Development 135:1189-1199.

Pak DT, Yang S, Rudolph-Correia S, Kim E, Sheng M (2001) Regulation of denritic spine morphology by SPAR, a PSD-95-associated RapGAP. Neuron 31:289-303.

Perez RG, Zheng H, Van der Ploeg LH, Koo EH (1997) The $\beta$-amyloid precursor protein of Alzheimer's disease enhances neuron viability and modulates neuronal polarity. J Neurosci 17:9407-9414.

Pramatarova A, Ochalski PG, Lee CH, Howell BW (2006) Mouse disabled 1 regulates the nuclear position of neurons in a Drosophila eye model. Mol Cell Biol 26:1510-1517.

Pramatarova A, Chen K, Howell BW (2008) A genetic interaction between the APP and Dabl genes influences brain development. Mol Cell Neurosci 37:178-186.

Qiu S, Weeber EJ (2007) Reelin signaling facilitates maturation of CA1 glutamatergic synapses. J Neurophysiol 97:2312-2321.

Qiu S, Zhao LF, Korwek KM, Weeber EJ (2006) Differential reelin-induced enhancement of NMDA and AMPA receptor activity in the adult hippocampus. J Neurosci 26:12943-12955.

Qiu WQ, Ferreira A, Miller C, Koo EH, Selkoe DJ (1995) Cell-surface $\beta$-amyloid precursor protein stimulates neurite outgrowth of hippocampal neurons in an isoform-dependent manner. J Neurosci 15:2157-2167.

Qiu Z, Strickland DK, Hyman BT, Rebeck GW (2002) $\alpha 2$-Macroglobulin exposure reduces calcium responses to $N$-methyl-D-aspartate via low density lipoprotein receptor-related protein in cultured hippocampal neurons. J Biol Chem 277:14458-14466.

Sabo SL, Ikin AF, Buxbaum JD, Greengard P (2003) The amyloid precursor protein and its regulatory protein, FE65, in growth cones and synapses in vitro and in vivo. J Neurosci 23:5407-5415.

Schmid RS, Jo R, Shelton S, Kreidberg JA, Anton ES (2005) Reelin, integrin and DAB1 interactions during embryonic cerebral cortical development. Cereb Cortex 15:1632-1636.

Selkoe DJ (2001) Alzheimer's disease: genes, proteins, and therapy. Physiol Rev 81:741-766.

Siemes C, Quast T, Kummer C, Wehner S, Kirfel G, Müller U, Herzog V (2006) Keratinocytes from APP/APLP2-deficient mice are impaired in proliferation, adhesion and migration in vitro. Exp Cell Res 312:1939-1949.

Small DH, Clarris HL, Williamson TG, Reed G, Key B, Mok SS, Beyreuther K, Masters CL, Nurcombe V (1999) Neurite-outgrowth regulating func- 
tions of the amyloid protein precursor of Alzheimer's disease. J Alzheimers Dis 1:275-285.

Wei L, Wang L, Carson JA, Agan JE, Imanaka-Yoshida K, Schwartz RJ (2001) beta1 integrin and organized actin filaments facilitate cardiomyocytespecific RhoA-dependent activation of the skeletal alpha-actin promoter. FASEB J 15:785-796.

Wirths O, Multhaup G, Czech C, Blanchard V, Tremp G, Pradier L, Beyreuther K, Bayer TA (2001) Reelin in plaques of beta-amyloid precursor protein and presenilin-1 double-transgenic mice. Neurosci Lett 316:145-148.

Yamazaki T, Koo EH, Selkoe DJ (1997) Cell surface amyloid $\beta$-protein precursor colocalizes with $\beta 1$ integrins at substrate contact sites in neural cells. J Neurosci 17:1004-1010.

Young-Pearse TL, Bai J, Chang R, Zheng JB, LoTurco JJ, Selkoe DJ (2007)
A critical function for $\beta$-amyloid precursor protein in neuronal migration revealed by in utero RNA interference. J Neurosci 27:14459-14469.

Young-Pearse TL, Chen AC, Chang R, Marquez C, Selkoe DJ (2008) Secreted APP regulates the function of full-length APP in neurite outgrowth through interaction with integrin betal. Neural Dev 3:15.

Zheng H, Jiang M, Trumbauer ME, Hopkins R, Sirinathsinghji DJ, Stevens KA, Conner MW, Slunt HH, Sisodia SS, Chen HY, Van der Ploeg LH (1996) Mice deficient for the amyloid precursor protein gene. Ann N Y Acad Sci 777:421-426.

Zisman S, Marom K, Avraham O, Rinsky-Halivni L, Gai U, Kligun G, Tzarfaty-Majar V, Suzuki T, Klar A (2007) Proteolysis and membrane capture of F-spondin generates combinatorial guidance cues from a single molecule. J Cell Biol 178:1237-1249. 